\title{
Co-sputtered $\mathrm{Pt}_{\mathrm{x}} \mathrm{Pd}_{\mathrm{y}} \mathrm{Al}_{\mathrm{z}}$ thin film electrocatalysts for the production of hydrogen via $\mathrm{SO}_{2}(\mathrm{aq})$ electro-oxidation
}

\author{
A. Falch ${ }^{\mathrm{a}}$, V.A. Badets ${ }^{\mathrm{b}}$, C. Labrugère ${ }^{\mathrm{c}}$, R.J. Kriek ${ }^{\mathrm{a} *}$ \\ ${ }^{a}$ Electrochemistry for Energy \& Environment Group, Research Focus Area: Chemical Resource Beneficiation \\ (CRB), North-West University, Private Bag X6001, Potchefstroom, 2520, South Africa \\ bISM, CNRS UMR 5255, University of Bordeaux, F-33400 Talence, France \\ 'PLACAMAT UMS 3626 CNRS, University of Bordeaux, 87 av. Albert SCHWEITZER, 33608 PESSAC \\ Cédex-FRANCE
}

\begin{abstract}
A co-sputtered $\mathrm{Pt}_{x} \mathrm{Pd}_{y} \mathrm{Al}_{\mathrm{z}}$ ternary system was investigated for potential use as anode catalyst for the electrooxidation of aqueous sulphur dioxide $\left(\mathrm{SO}_{2}\right)$, a key reaction in the hybrid sulphur (HyS) process for splitting water into hydrogen and oxygen. Combining the noble metals $\mathrm{Pt}$ and $\mathrm{Pd}$ with $\mathrm{Al}$ resulted in no significant improvement in onset potential, however, current output was improved for the majority of the electrocatalysts evaluated. Of these electrocatalysts only a single ternary composition exhibited improved stability when compared to pure Pt. It was found that a combination of $\mathrm{Pt}_{40} \mathrm{Pd}_{57} \mathrm{Al}_{3}$ (annealed at $900{ }^{\circ} \mathrm{C}$ ) exhibited superior performance when compared to pure $\mathrm{Pt}$ and the previously determined best binary electrocatalyst, i.e. $\mathrm{Pt}_{3} \mathrm{Pd}_{2}$. Current density $(\mathrm{mA} \cdot \mathrm{mg}$ $\mathrm{Pt}^{-1}$ ) increased from 108.11 to 181.21 and finally to 396.73 for $\mathrm{Pt}, \mathrm{Pt}_{3} \mathrm{Pd}_{2}$ and $\mathrm{Pt}_{40} \mathrm{Pd}_{57} \mathrm{Al}_{3}$ respectively, indicating an increase in activity that correlates with a decrease in Pt content. Atomic force microscopy (AFM) revealed an increase in surface roughness for $\mathrm{Pt}_{1} \mathrm{Pt}_{3} \mathrm{Pd}_{2}$ and $\mathrm{Pt}_{40} \mathrm{Pd}_{57} \mathrm{Al}_{3}$, while the occurrence of metal interaction and certain degrees of $\mathrm{Al}$ migration (a result of annealing) was confirmed for $\mathrm{Pt}_{40} \mathrm{Pd}_{57} \mathrm{Al}_{3}$ by $\mathrm{X}$-ray photoelectron spectroscopy (XPS) and X-ray diffraction analysis (XRD).
\end{abstract}

\section{Keywords: $\mathrm{SO}_{2}$ electro-oxidation, hydrogen production, electrocatalyst, high-throughput screening}

*Corresponding Author: E-mail: cobus.kriek@nwu.ac.za, Tel no: +27 (0)18 2992345

\section{Introduction}

Hydrogen, the only non-carbon containing energy carrier, is the most abundant atom on earth ${ }^{1}$ and is considered as the ultimate clean energy carrier to be generated from renewable resources ${ }^{2}$. The range of hydrogen production processes can roughly be divided into hydrocarbon-based (steam-methane reforming and coal gasification), nonhydrocarbon based (water electrolysis and thermochemical water decomposition) and integrated (steam-methane reforming linked to non-hydrocarbon based) ${ }^{3}$. As hydrogen is only found as part of compounds on earth, it is fairly energy intensive to separate hydrogen into its molecular form ${ }^{1}$, and goes hand in hand with huge amounts of environmental pollutants being emitted to the atmosphere. If, however, hydrogen can be returned/produced as part of a remediation process of these detrimental environmental pollutants, a portion of the energy input for the remediation process can be returned in the form hydrogen. This is exactly what the hybrid sulphur (HyS) cycle, a thermo-electrochemical water splitting process, accomplishes, through the electrochemical oxidation of aqueous sulphur dioxide (Figure 1). Thermochemical processes produce hydrogen through a series of chemical reactions with water-splitting being the net reaction. Since hydrocarbons are not used in these thermochemical processes no harmful emissions such as carbon dioxide $\left(\mathrm{CO}_{2}\right)$ are produced, with the hydrogen produced being extremely pure $^{4}$. There are various thermochemical cycles (a combination of thermochemical and electrochemical reactions ${ }^{5}$ ) that can produce hydrogen from water with the HyS cycle (reactions 1 - 4) being the most promising ${ }^{4,6-8}$.

Thermal decomposition: $\mathrm{H}_{2} \mathrm{SO}_{4} \rightarrow \mathrm{SO}_{2}+1 / 2 \mathrm{O}_{2}+\mathrm{H}_{2} \mathrm{O}$

Anode reaction:

$\mathrm{SO}_{2}+2 \mathrm{H}_{2} \mathrm{O} \rightarrow \mathrm{H}_{2} \mathrm{SO}_{4}+2 \mathrm{H}^{+}+2 \mathrm{e}^{-}$

Cathode reaction:

$2 \mathrm{H}^{+}+2 \mathrm{e}^{-} \rightarrow \mathrm{H}_{2}$

Net electrolysis reaction: $\mathrm{SO}_{2}+2 \mathrm{H}_{2} \mathrm{O} \rightarrow \mathrm{H}_{2} \mathrm{SO}_{4}+\mathrm{H}_{2}$

Net cycle reaction:

$\mathrm{H}_{2} \mathrm{O} \rightarrow \mathrm{H}_{2}+1 / 2 \mathrm{O}_{2}$ 


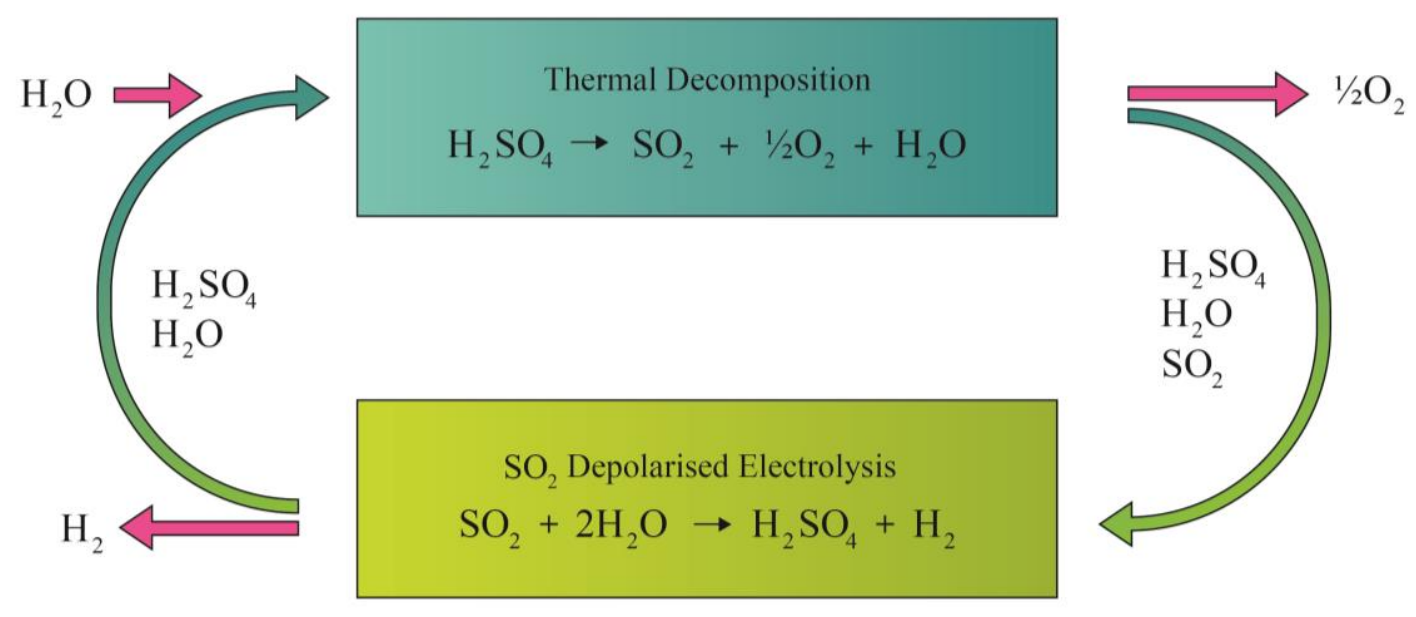

Figure 1: The thermo-electrochemical HyS cycle for the splitting of water.

The HyS cycle undergone extensive development in the 1970s 9,10 and 1980s ${ }^{10,11}$. For the subsequent 20 years, further development nearly ceased as advanced nuclear technologies gained increased interest ${ }^{10}$. After this period, interest in the HyS cycle revived and the HyS cycle was subsequently rated first among 115 thermochemical cycles considered ${ }^{12}$. Interest in the HyS cycle results from the fact that, whereas the anodic reaction for regular water electrolysis occurs at a standard potential of $1.23 \mathrm{~V}$ (SHE) ${ }^{13}$, the anodic reaction for $\mathrm{SO}_{2}$ depolarised electrolysis (SDE) occurs at a standard potential of $0.17 \mathrm{~V}$ (SHE) ${ }^{14}$, which translates into an energy gain of more than one volt ${ }^{7,15}$. In SDE the rate determining step occurs at the anode, which results in the anode attributing to the inefficiencies of the SDE ${ }^{16}$. To this regard, an optimal operational target of $500 \mathrm{~mA} \cdot \mathrm{cm}^{-2}$, at a cell potential of approximately $0.6 \mathrm{~V}$, has been proposed for SDE by Gorensek and Summers ${ }^{7,}{ }^{17}$. This target can potentially be achieved through the development of an effective electrocatalyst for the anodic electro-oxidation of $\mathrm{SO}_{2}$ and to that regard the properties of the anode is regarded as pivotal for improving the entire HyS process ${ }^{18,19}$.

While platinum is generally considered the standard anode catalyst for the $\operatorname{SDE}^{8,16}$, efforts are underway to identify an electrocatalyst other than platinum (see ${ }^{20,21}$ for a detailed list of investigated catalysts). As Pt is costly the development and implementation of a catalyst with increased or equal catalytic activity and reduced cost (less Pt) will be advantageous. Platinum content could be reduced by alloying/combining it with either a more cost effective noble metal or base metals in an effort to still maintain acceptable catalytic activity ${ }^{20,21}$. An earlier investigation by us (employing sputtered thin films) has shown that Pt content can indeed be reduced by combination with $\mathrm{Pd}$, i.e. $\mathrm{Pt}_{\mathrm{x}} \mathrm{Pd}_{\mathrm{y}}$, without sacrificing electrocatalytic activity ${ }^{21}$. A thin film combination of $\mathrm{Pt}_{3} \mathrm{Pd}_{2}$ has specifically been found to exhibit competitive performance compared to pure Pt for the electro-oxidation of aqueous $\mathrm{SO}_{2}$ with annealing further improving performance ${ }^{21}$. For this study aluminium (Al) was introduced as a third component in an attempt to lower the content of both Pt and Pd (both noble metals). Al is considered a metal of great electrochemical potential ${ }^{22}$ and a study by Lee ${ }^{23}$ on $\mathrm{Pt}$ and $\mathrm{Al}$ combinations proved that only small amounts of $\mathrm{Al}$ is effective in improving catalytic performance towards aqueous $\mathrm{SO}_{2}$ electro-oxidation. This study by Lee was brief and no subsequent investigations were pursued ${ }^{24}$. For this investigation we employed combinatorial evaporative sputtering and high-throughput parallel screening in search of $\mathrm{Pt}_{\mathrm{x}} \mathrm{Pd}_{\mathrm{y}} \mathrm{Al}_{\mathrm{z}}$ electrocatalysts for the electro-oxidation of $\mathrm{SO}_{2}$. Identified compositions that merit more thorough investigation were evaluated employing conventional methods.

\section{Experimental}

\subsection{Preparation, deposition, screening and annealing of thin films}

The wafer and glassy carbon preparation, thin film deposition and electrochemical testing have previously been described in-depth ${ }^{20,21}$. Employing a built-in quartz crystal microbalance (QCM) ${ }^{20}$ and Pt, Pd and Al targets, all with a purity of $99.99 \%$ (ACI alloys), the conditions for physical vapor deposition (PVD) were derived for the chosen compositions. The thin films $(\sim 60 \mathrm{~nm})$ were subsequently deposited in triplicate by PVD, onto an annular arrangement (Patent Application No. 2015/08424) of 64 square working electrode pads $\left(0.09 \mathrm{~cm}^{2}\right.$ each), developed through photolithography ${ }^{20}$ (Figure 2). The electrode pads were connected by a network of traces to individual rectangular pin pads on the outer perimeter of the wafer. The network of traces were provided with reinforced bending points to prevent braking of the lines/traces. For the conventional electrochemical testing glassy carbon inserts $\left(0.196 \mathrm{~cm}^{2}\right.$ each) were employed as substrate onto which the thin metal films were deposited. 
Electrochemical testing was performed on the wafer containing the various thin film compositions, in a dedicated electrochemical cell ${ }^{20}$, with each working electrode connected individually to a multichannel potentiostat (Arbin MSTAT) for high-throughput screening while conventional testing commenced in a standard three electrode setup ${ }^{21}$. Preconditioning was conducted in degassed 0.1 mol. $\mathrm{L}^{-1} \mathrm{HClO}_{4}$ (Merck), scanning from $0.041 \mathrm{~V}$ vs SHE to $1.441 \mathrm{~V}$ vs SHE starting at $\mathrm{E}_{\text {ocp }}$ (open circuit potential) for 25 cycles, followed by 3 cycles up to $1.741 \mathrm{~V}$ vs SHE and finally the first step was repeated but only for three cycles, employing a scan rate of $50 \mathrm{mV} . \mathrm{s}^{-1}$ respectively. Linear polarisation (LP) was conducted in 1 mol. $\mathrm{L}^{-1} \mathrm{H}_{2} \mathrm{SO}_{4}(\mathrm{Merck}, \mathrm{pH}=0.55)$ in the potential window $0.2 \mathrm{~V}$ vs SHE to $1.441 \mathrm{~V}$ vs SHE at a scan rate of $10 \mathrm{mV} . \mathrm{s}^{-1}$. This solution was degassed with $\mathrm{N}_{2}$ for 15 min prior to linear polarisation. A stock solution of 1 mol.L-1 $\mathrm{Na}_{2} \mathrm{SO}_{3}$ (Sigma Aldrich) was used as an in-situ $\mathrm{SO}_{2}$ source ${ }^{20}$. These electrochemistry testing parameters were identical for the thin films deposited onto the wafer and the glassy carbon inserts. In addition internal resistance (i-R) drop was measured to be $46 \Omega$ for the conventional electrochemical setup employing the various combination of thin films sputtered onto glassy carbon inserts. i-R compensation was intentionally not applied to LP scans as it damps current oscillations (as is observed for our catalyst (not shown)) which is specific to catalytic activity and relates to mechanistic phenomena ${ }^{25}$ (mechanistic investigation was not part of the scope). Subsequent to the deposition of the selected thin film combinations onto the glassy carbon substrates (designated with letters of the alphabet as a means to ease comprehension throughout the article), some were kept as fresh (as-deposited) thin films while the rest of the thin films were annealed ex-situ under an $\mathrm{Ar}$ atmosphere, employing a rapid thermal annealing oven (Accuthermo AW610), with the maximum temperatures ranging from $600{ }^{\circ} \mathrm{C}$ to $900{ }^{\circ} \mathrm{C}$ with intervals of $100{ }^{\circ} \mathrm{C}^{21}$.

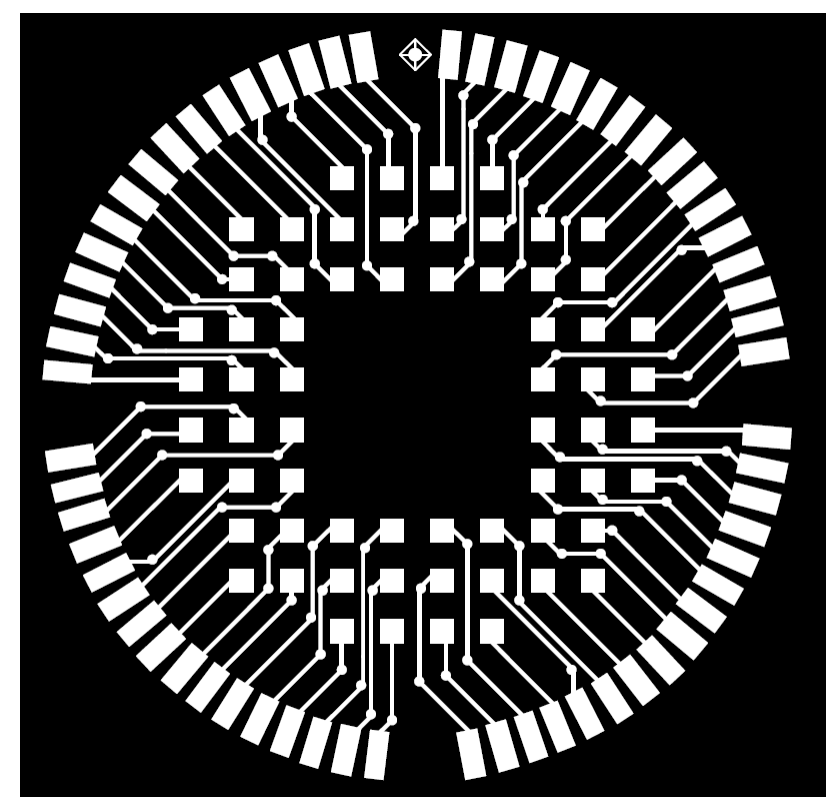

Figure 2: Annular arrangement of 64 square working electrode pads (Patent Application No. 2015/08424).

\subsection{Physical characterisation of thin films}

Energy-dispersive X-ray spectroscopy (EDX, employing INCA software) analysis, in moving average mode employing a collection time of $100 \mathrm{~s}$ and a $15 \mathrm{keV}$ electron source, was conducted in triplicate before and after electrochemical testing, so as to evaluate thin film composition. Atomic force microscopy (AFM, Nanoscope V Multimode from Veeco) was used to investigate surface roughness, deriving various surface roughness parameters by employing Nanoscope Analysis (Veeco) software. In addition, surface properties of the thin films were characterised employing X-ray photoelectron spectroscopy (XPS). A Thermo Fisher Scientific K-ALPHA spectrometer was used for surface analysis with a monochromatised $\mathrm{Al} \mathrm{K \alpha}$ source $(\mathrm{h} v=1486.6 \mathrm{eV})$ and a 200 micrometer spot size. A pressure of $10^{-7} \mathrm{~Pa}$ was reached in the chamber when transferring the samples. The full spectra $(0-1100 \mathrm{eV})$ were obtained with a constant pass energy of $200 \mathrm{eV}$ and high resolution spectra $(\mathrm{C} 1 \mathrm{~s}, \mathrm{Pd} 3 \mathrm{p}-$ $\mathrm{O} 1 \mathrm{~s}, \mathrm{Al} 2 \mathrm{p}-\mathrm{Pt} 4 \mathrm{f}, \mathrm{Pd} 3 \mathrm{~d}, \mathrm{Al} 2 \mathrm{~s}$ ) at a constant pass energy of $40 \mathrm{eV}$. Charge neutralisation was applied during analysis. Sputtering was performed with $\mathrm{Ar}^{+}$ions at $500 \mathrm{eV}$. High resolution spectra were fitted and quantified (Scofield sensitivity factors used for quantification) using the AVANTAGE software provided by Thermo Fisher Scientific. 


\section{Results and discussion}

\subsection{Combinatorial sputtering and high-throughput screening of the $\operatorname{Pt}_{\mathbf{x}} \mathbf{P d}_{\mathbf{y}} \mathbf{A l}_{\mathrm{z}} \operatorname{system}$}

With the focus on identifying a possible ternary anode composition for application in the electro-oxidation of $\mathrm{SO}_{2}$, $\mathrm{Pt}_{\mathrm{x}} \mathrm{Pd}_{\mathrm{y}}$ compositions were evaluated previously ${ }^{20,21}$ and characterised so as to establish a standard for comparison with ternary $\mathrm{Pt}_{\mathrm{x}} \mathrm{Pd}_{\mathrm{y}} \mathrm{Al}_{\mathrm{z}}$ anode compositions ${ }^{26}$. The initial binary combinations investigated include a wide compositional range $\left(\mathrm{Pt}_{\mathrm{x}} \mathrm{Pd}_{\mathrm{y}}\right)$ that spanned from pure $\mathrm{Pt}$ to pure $\mathrm{Pd}$ using mainly $10 \%$ content increments (refer to reference ${ }^{20}$ for in-depth details). $\mathrm{Pt}_{3} \mathrm{Pd}_{2}$ was identified to be the optimum binary composition and extensive characterisation was conducted on it ${ }^{21}$, with annealed $\mathrm{Pt}_{3} \mathrm{Pd}_{2}$ (at $800{ }^{\circ} \mathrm{C}$ ) proving to be a worthy contender to compete with pure $\mathrm{Pt}$ for the electro-oxidation of $\mathrm{SO}_{2}$. In producing a ternary electrocatalyst the combination of $\mathrm{Pt}$ and Pd with a base metal will result in an electrocatalyst containing less noble metal with $\mathrm{Al}$ making up the balance. Due to the vast number of electrocatalyst combinations which can statistically be formulated using the three components, $\mathrm{Pt}, \mathrm{Pd}$, and $\mathrm{Al}$, our selection of electrocatalysts to be subjected to high-throughput screening was aligned with the high-throughput experimental planning categorized by R. Potyrailo ${ }^{27}$. This includes hierarchical developing the experiment with increasing focus covering a space of interest ${ }^{27}$. Employing the finding of our previous work, that a $\mathrm{Pt}_{3} \mathrm{Pd}_{2}$ annealed at $800{ }^{\circ} \mathrm{C}$ exhibited competing performance, as a guideline for a possible ternary anode composition which contains a base metal, ternary compositions were mainly focused but not limited to the area were $\mathrm{Pt}$ is less than $60 \%$, Pd less than $40 \%$ (i.e. $\mathrm{Pt}_{3} \mathrm{Pd}_{2}$ ) and random $\mathrm{Al}$ content. $\mathrm{Al}$, however, could not be increased above $60 \%$ as (i) Al deposits at a much lower rate in contrast to Pt and $\mathrm{Pd}$ resulting in very long deposition times, while operating the PVD apparatus at its limit, (ii) Al is not very resistant in strong acidic environments with degradation being almost immediate in sulphuric acid, and (iii) a report found in literature, on $\mathrm{Pt}$ and $\mathrm{Al}$ combinations, proved that only small amounts of $\mathrm{Al}$ is effective in improving catalytic performance ${ }^{23}$. Linear polarisation response of the various compositions were obtained through high-throughput parallel screening, which is a simple means of quickly identifying an active composition that may work well in the SDE environment. The average of the polarisation graphs (conducted in triplicate) were used to determine the onset potential for each ratio employing the method reported by Cooper \& McGinn with the current density based on (a) geometric area ${ }^{20,26,28}$, and (b) mass Pt present in the thin film.

Before and immediately subsequent to electrochemical testing each of the catalyst pads were visually evaluated for signs of corrosion. Some of the compositions did corrode during electrochemical testing (Figure 3), which was also observed by Cooper \& McGinn for their Pt-Ru-W thin film anode catalysts for direct methanol fuel cells ${ }^{26}$.

a)

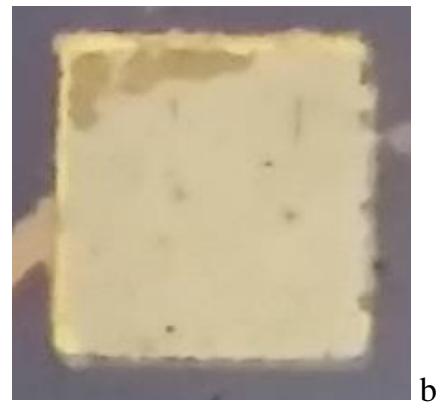

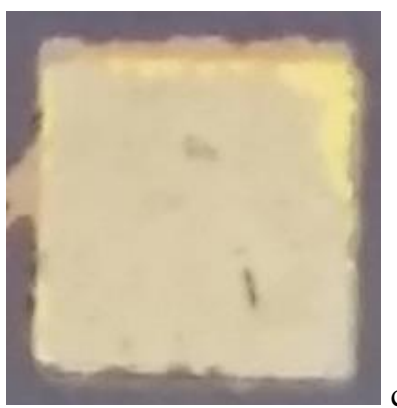

c)

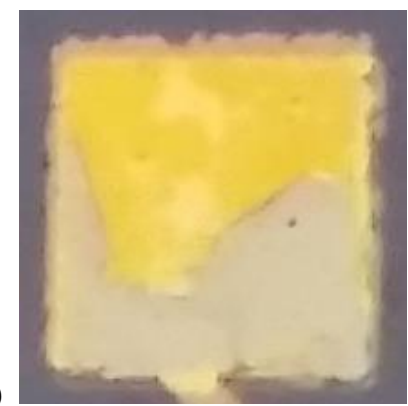

Figure 3: Examples of varying degrees of corrosion occurring after linear polarisation for (a) $\mathbf{P t}_{34} \mathbf{P d}_{22} \mathrm{Al}_{44}$, (b) $\mathrm{Pt}_{43} \mathrm{Pd}_{46} \mathrm{Al}_{11}$, and (c) Al.

In the event that the greatest portion of the pad revealed corrosion, it was not included in the results, as it would in essence be the gold circuit that participated in the electro-oxidative reaction. Gold shows a high onset potential for $\mathrm{SO}_{2}$ electro-oxidation, hence obtaining low onset potentials eliminated the possible interference of gold. Onset potential, as a means of evaluating catalyst activity, is a suitable measure in the event of possible corrosion as it is not influenced by any change in surface roughness ${ }^{26}$. As only some catalyst pads revealed severe signs of corrosion, which were subsequently eliminated, current density based on geometric area and mass of Pt present in the thin film were also employed to evaluate thin film combinations. Current density, in contrast to onset potential, is influenced by both surface roughness and composition and by applying both these parameters to 
identify thin film candidates during the screening phase, limited any systematic errors made. Screening of the various thin film combinations, for the electro-oxidation of $\mathrm{SO}_{2}$, are summarised in Figure 4 as ternary contour plots in terms of (a) onset potential (V), (b) current density $\left(\mathrm{mA} . \mathrm{cm}^{-2}\right)$, and (c) mass-specific current density $\left(\mathrm{mA} . \mu \mathrm{g} \mathrm{Pt}^{-1}\right)$. Employing these criteria eight thin film composition, three based on lowest onset potential value, three based on highest geometric current density (normalised by geometric area), and two based on highest massspecific current density (normalised by Pt mass), were selected for additional testing employing conventional testing techniques with glassy carbon inserts as substrate.
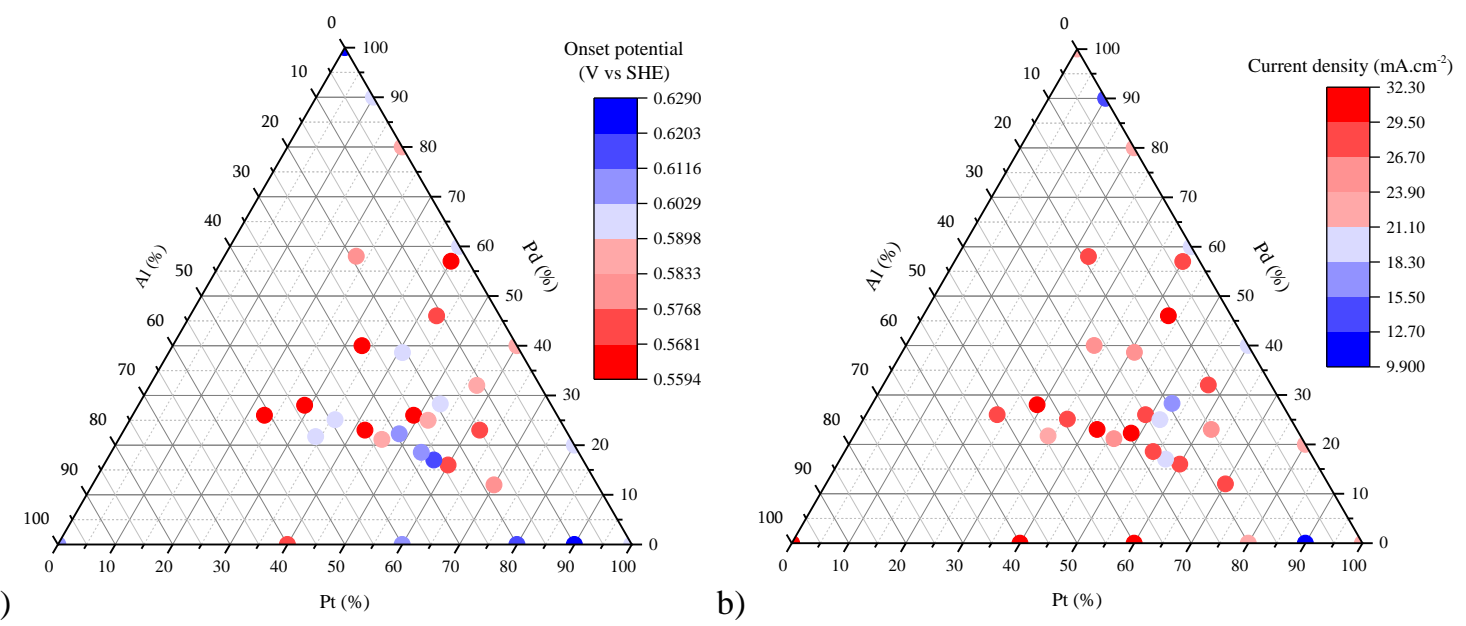

a)

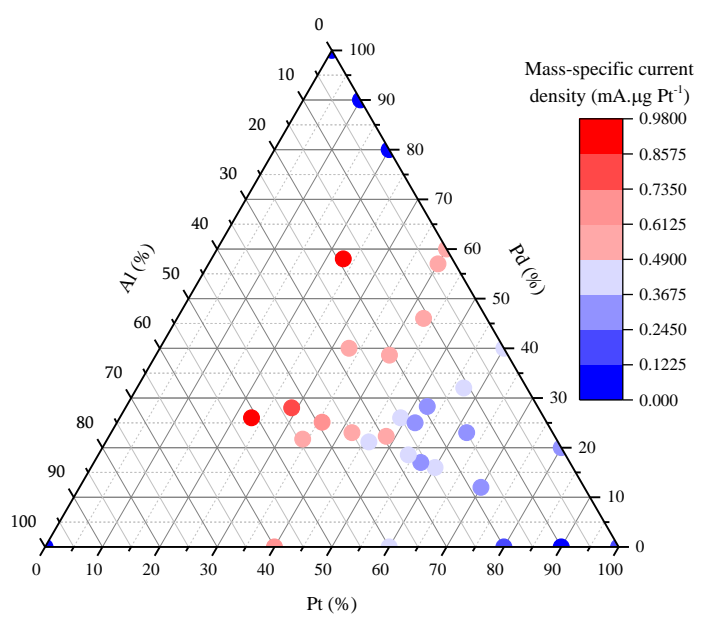

Figure 4: Ternary contour plots for (a) onset potential, (b) current density normalised by geometric area, and (c) massspecific normalised current density, towards $\mathrm{SO}_{2}$ electro-oxidation for the $\mathbf{P t}_{\mathbf{x}} \mathbf{P d}_{\mathbf{y}} \mathrm{Al}_{\mathrm{z}} \mathbf{S y s t e m}_{\text {s }}$

\subsection{Composition of the thin films prior to conventional electrochemical testing}

The bulk stoichiometry of the eight best electrocatalysts was investigated in triplicate by EDX, both before and after annealing. EDX analysis revealed that the expected theoretical compositions, predicted by employing the built-in QCM, correlate well with the actual sputtered bulk stoichiometry (Figure 5). No difference between asdeposited thin films and their corresponding annealed states were observed. 


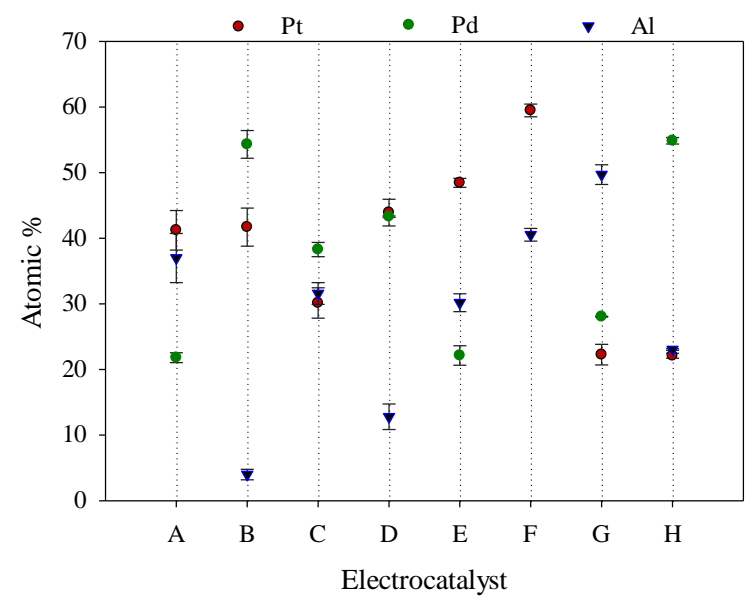

Figure 5: EDX after sputtering verifying that the actual sputtered ratios correlate with the expected sputtered ratios

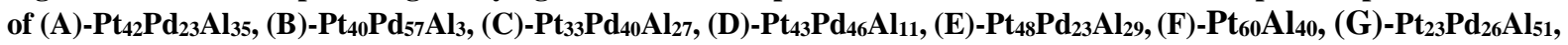
and $(\mathrm{H})-\mathrm{Pt}_{23} \mathrm{Pd}_{58} \mathrm{Al}_{19}$.

\subsection{Conventional electrochemical evaluation}

\subsubsection{Linear polarisation and subsequent EDX characterisation}

Employing physical vapour deposition and high-throughput screening accelerates the complex process of new catalyst design and improves performance identification. However, it is not sufficiently suited for in-depth investigation and characterisation, and conventional methods, such as rotating disk electrode (RDE) linear polarisation, are more suitable. Hence, Figure 6 exhibits the electrocatalytic performance of the eight selected thin films (in the as-deposited (AD) and annealed state (on glassy carbon as substrate)) that did not show signs of corrosion (mainly in the form of delamination) during/after electrochemical testing. (I)-700 ${ }^{\circ} \mathrm{C}$, referring to $\mathrm{Pt}$, and previously identified $(\mathrm{J})-800{ }^{\circ} \mathrm{C}$, referring to $\mathrm{Pt}_{3} \mathrm{Pd}_{2}$, are taken as the baseline to which all ternary combinations are compared against. In general, it is evident that no significant improvement in onset potential was achieved, with the majority of electrocatalysts exhibiting similar onset potentials (within error), when compared to (I)-700 ${ }^{\circ} \mathrm{C}$ and (J)-800 ${ }^{\circ} \mathrm{C}$. However, (E)-AD, $700{ }^{\circ} \mathrm{C}, 800{ }^{\circ} \mathrm{C}$ and (D)-AD performed well. As the results obtained from onset potential are not sufficient for identifying an alternative electrocatalyst, mass-specific current density was also investigated. From Figure 6 it is evident that the majority of the ternary electrocatalysts exhibits an increase in current density. Compared to the baseline, i.e. $\mathrm{Pt}$ and $\mathrm{Pt}_{3} \mathrm{Pd}_{2}, \mathrm{Pt}_{40} \mathrm{Pd}_{57} \mathrm{Al}_{3}$ (annealed at $900{ }^{\circ} \mathrm{C}$ ) performed the best in that current density (mA.mg Pt ${ }^{-1}$ ) increased from 108.11, to 181.21 and finally to 396.73 for $\mathrm{Pt} \mathrm{Pt}_{3} \mathrm{Pd}_{2}$ and $\mathrm{Pt}_{40} \mathrm{Pd}_{57} \mathrm{Al}_{3}$ respectively, indicating an increase in activity that correlates with a decrease in Pt content (Figure 7).

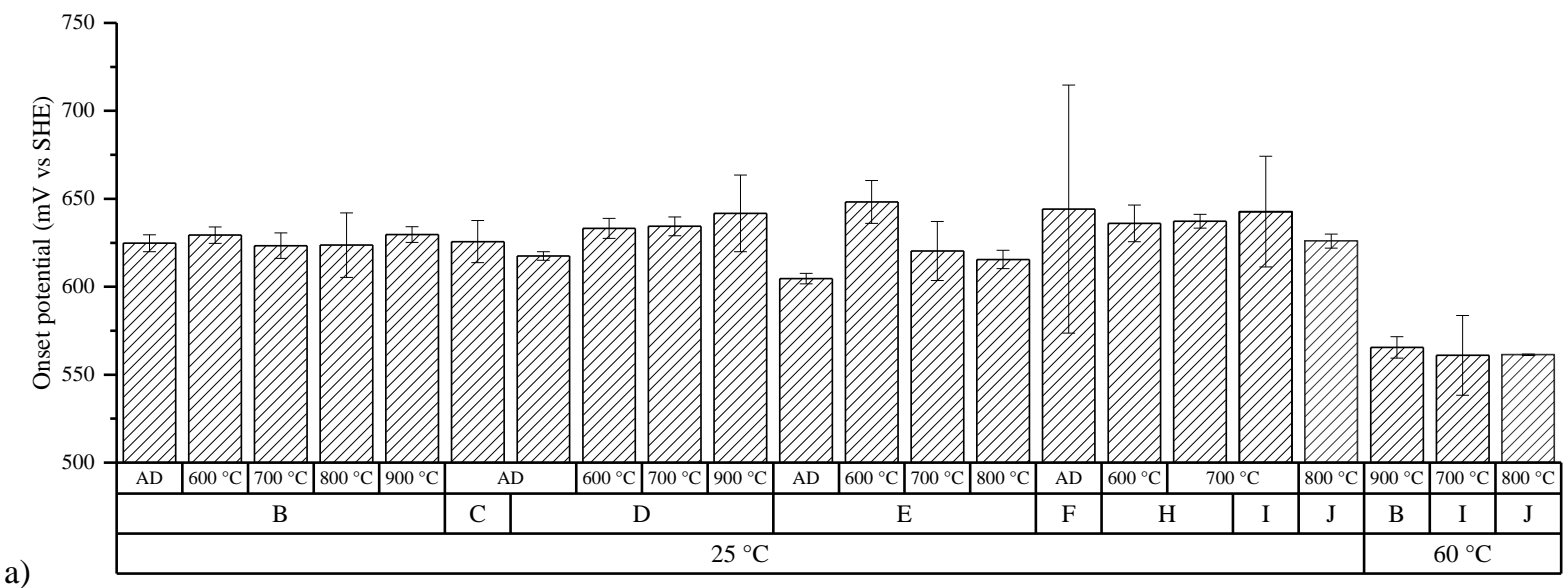




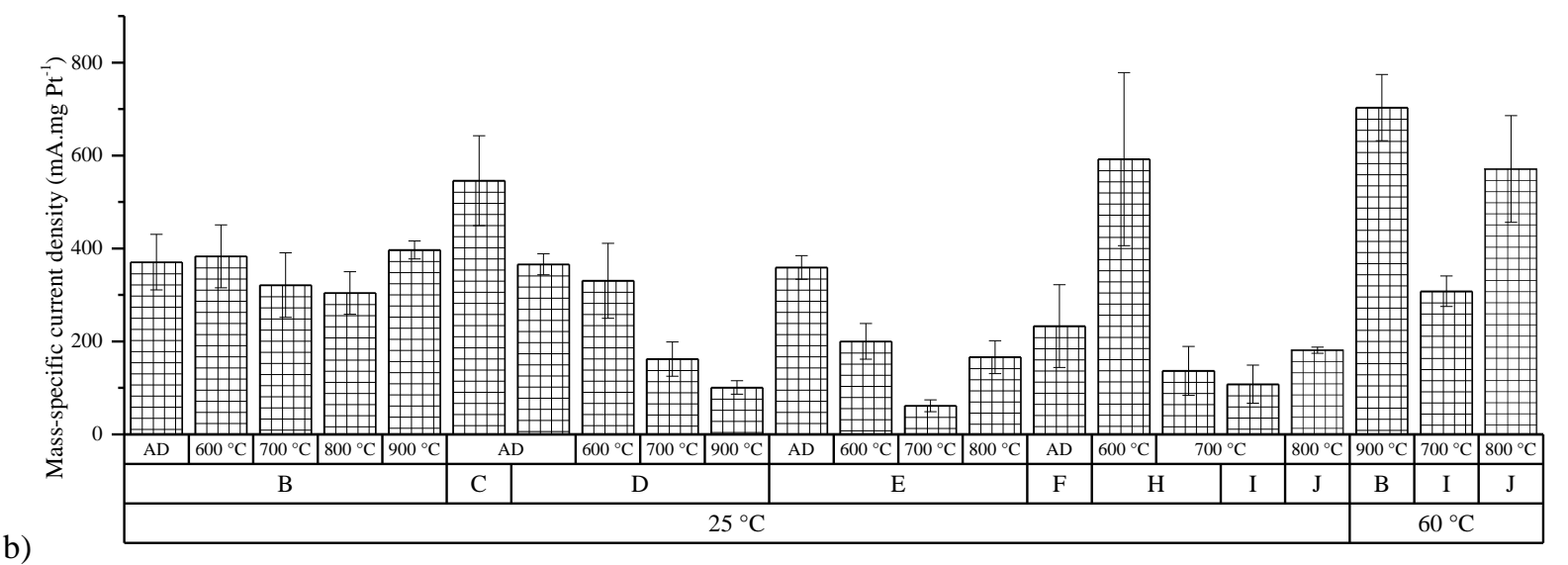

Figure 6: Onset potential values (a) and mass-specific current density values (b) for (B)-Pt $\mathbf{t}_{40} \mathbf{P d}_{57} \mathrm{Al}_{3},\left(\mathrm{C}_{\text {)-Pt }} \mathbf{P t}_{33} \mathbf{P d}_{40} \mathrm{Al}_{27}\right.$, (D)-Pt ${ }_{43} \mathbf{P d}_{46} \mathrm{Al}_{11},(\mathrm{E})-\mathrm{Pt}_{48} \mathrm{Pd}_{23} \mathrm{Al}_{29},(\mathrm{~F})-\mathrm{Pt}_{60} \mathrm{Al}_{40},(\mathrm{H})-\mathrm{Pt}_{23} \mathbf{P d}_{58} \mathrm{Al}_{19}$, (I)-Pt, and (J)-Pt $3 \mathbf{P d}_{2}$.

Subsequent to electrochemical testing (Figure 6) the thin film electrocatalysts were analysed by EDX so as to evaluate any change in composition that could not be visually detected (an indication of short term stability). Overall, all the catalysts exhibit a slight change in compositional ratio with no specific trend (Figure 8), when compared to the compositional ratios directly after sputtering (Figure 5), with (B)-AD, (F)-AD, $(\mathrm{H})-600{ }^{\circ} \mathrm{C}$ and (H)-700 ${ }^{\circ} \mathrm{C}$ showing the largest deviation in compositional ratio. This is however not sufficient in identifying a stable electrocatalyst, and additional evaluation on the stability is required. In an attempt to identify a stable electrocatalyst, in conjunction with having a low onset potential and acceptable current output, consecutive cycling in a sulphuric acid environment was conducted (Figure 9). For all the electrocatalysts under investigation, the only electrocatalyst that exhibited improved stability, compared to (I)-700 ${ }^{\circ} \mathrm{C}$ and $(\mathrm{J})-800{ }^{\circ} \mathrm{C}$, was $(\mathrm{B})-900{ }^{\circ} \mathrm{C}$, lasting about 1.4 times longer. Taking all three parameters (onset potential, mass-specific activity, and stability) into consideration that are indicative of an improved electrocatalyst, (B)- $900{ }^{\circ} \mathrm{C}$ can therefore be considered the ternary candidate exhibiting the most potential in competing with (I)-700 ${ }^{\circ} \mathrm{C}$ and $(\mathrm{J})-800{ }^{\circ} \mathrm{C}$.

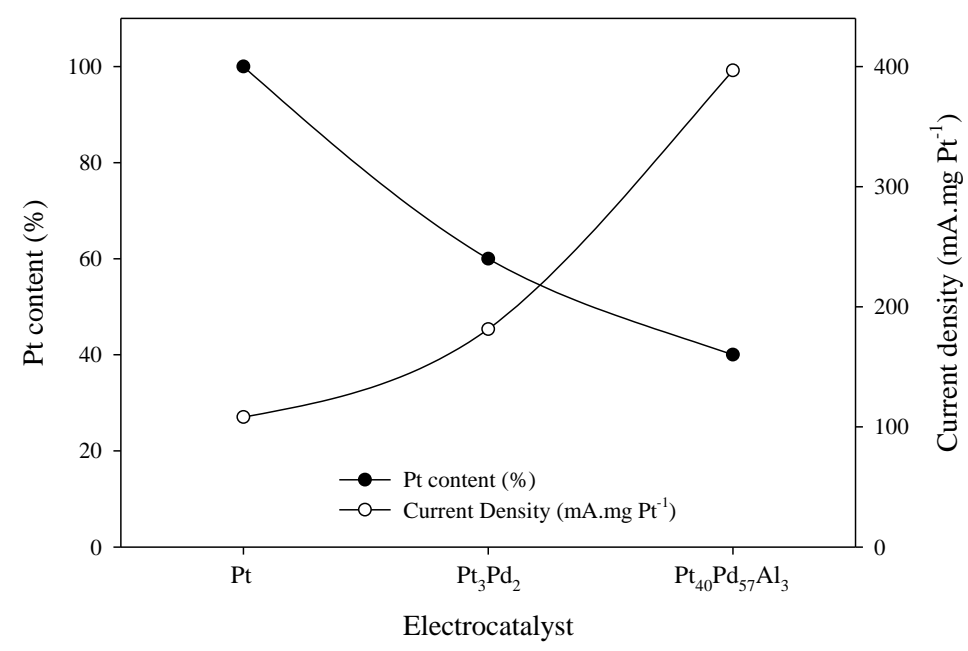

Figure 7: Correlation of current density (mA.mg Pt $\left.{ }^{-1}\right)$ with Pt content (\%). 


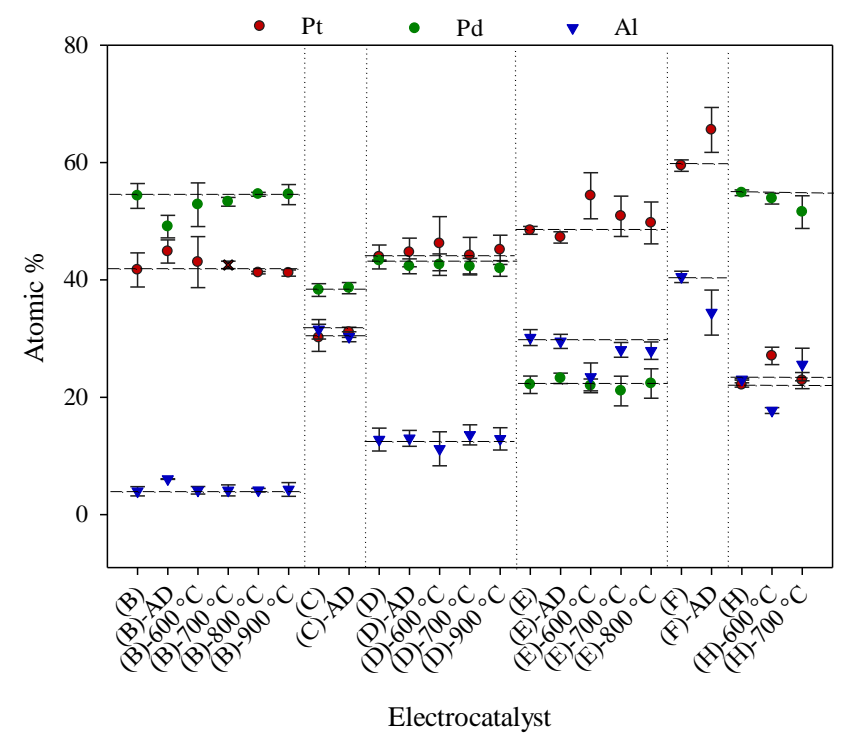

Figure 8: EDX analysis subsequent to $\mathrm{LP}$ runs for $(\mathrm{B})-\mathrm{Pt}_{40} \mathrm{Pd}_{57} \mathrm{Al}_{3},(\mathrm{C})-\mathrm{Pt}_{33} \mathrm{Pd}_{40} \mathrm{Al}_{27},(\mathrm{D})-\mathrm{Pt}_{43} \mathrm{Pd}_{46} \mathrm{Al}_{11},(\mathbf{E})-\mathrm{Pt}_{48} \mathbf{P d}_{23} \mathrm{Al}_{29}$, (F)-Pt60Al 40 , and (H)-Pt 23 Pd58Al 19.

To put (B)- $900{ }^{\circ} \mathrm{C}$ further to the test, it was subsequently evaluated under an increased electrolyte temperature of $60{ }^{\circ} \mathrm{C}$ (using a SCE reference electrode above this temperature is not advised, due to the instability of $\mathrm{Hg}_{2} \mathrm{Cl}_{2}$ ) with the results also being depicted in Figure 6 and Figure 9. At this elevated temperature the same phenomena was observed for (B)- $900{ }^{\circ} \mathrm{C}$, (I)- $700{ }^{\circ} \mathrm{C}$ and $(\mathrm{J})-800{ }^{\circ} \mathrm{C}$ as in the case of $25{ }^{\circ} \mathrm{C}$, with no significant difference in onset potential having been observed. However, an improved performance was evident in terms of current output and durability. The (B)-900 ${ }^{\circ} \mathrm{C}$ thin film (at $25^{\circ} \mathrm{C}$ ) furthermore exhibited totally different behavior in terms of visible signs of corrosion when compared to all the other tested electrocatalysts. This was evident in that the (B)$900{ }^{\circ} \mathrm{C}$ thin film (at $25^{\circ} \mathrm{C}$ ) dissolved gradually into solution (visually monitored until the film was so thin, that glassy carbon started to appear), keeping its active surface (Figure 10a) as only the thin film thickness decreased, while all the other electrocatalysts, including the target electrocatalysts ${ }^{21}$, clearly delaminated. (B)- $900{ }^{\circ} \mathrm{C}$ (at 60 ${ }^{\circ} \mathrm{C}$ ), in contrast, only started to exhibit the normal signs of delamination nearer to the end of its stability lifetime, with the last cycle subsequently being lower in the hydrogen adsorption/desorption region than the first cycle (Figure 10b), as a part of the thin film delaminated from the surface.

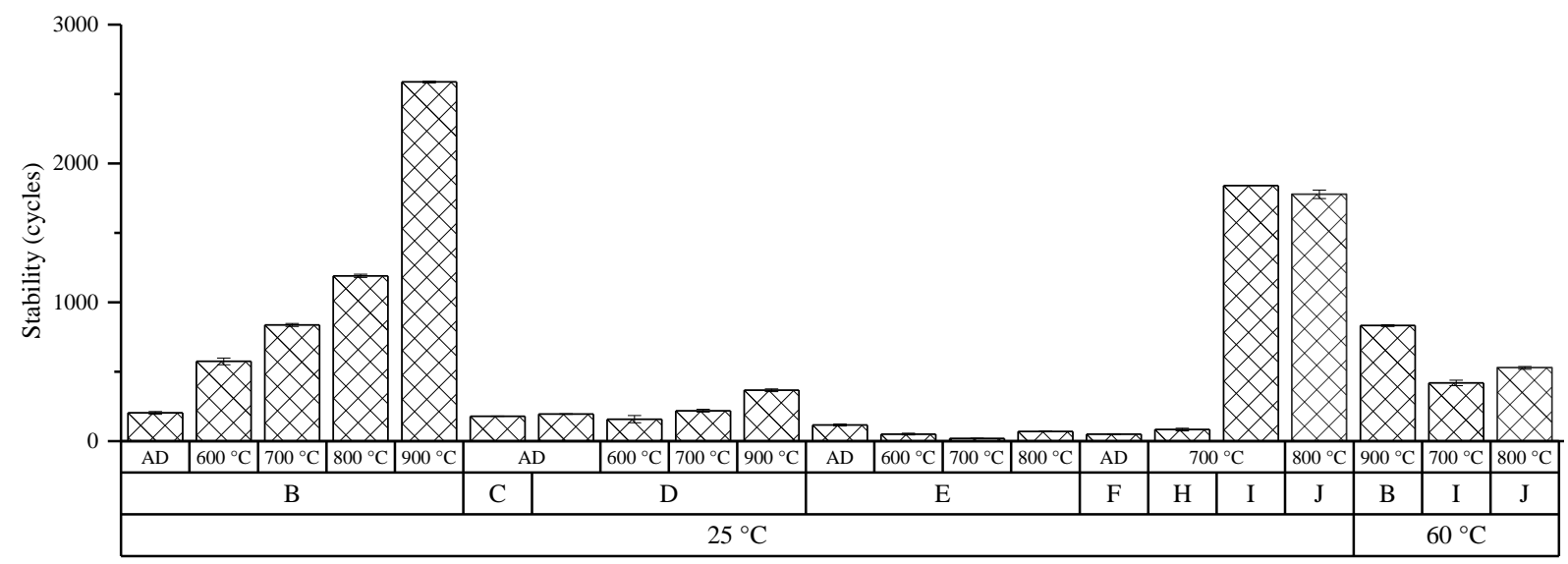

Figure 9: Consecutive cycling of thin film electrocatalyst for stability evaluation with (B)-Pt ${ }_{40} \mathbf{P d}_{57} \mathbf{A l}_{3},(C)-\mathbf{P t}_{33} \mathbf{P d}_{40} \mathbf{A l}_{27}$, (D)-Pt ${ }_{43} \mathbf{P d}_{46} \mathrm{Al}_{11},(E)-\mathbf{P t}_{48} \mathbf{P d}_{23} \mathrm{Al}_{29}$, (F)-Pt ${ }_{60} \mathrm{Al}_{40}$, (H)-Pt ${ }_{23} \mathbf{P d}_{58} \mathrm{Al}_{19}$, (I)-Pt, and (J)-Pt $\mathbf{P d}_{2}$. Conditions: scan rate of 100 $\mathrm{mV} . \mathrm{s}^{-1}$ and potential window of $0.041 \mathrm{~V}$ vs SHE to $1.441 \mathrm{~V}$ vs SHE at $25^{\circ} \mathrm{C}$ and $60{ }^{\circ} \mathrm{C}$. 

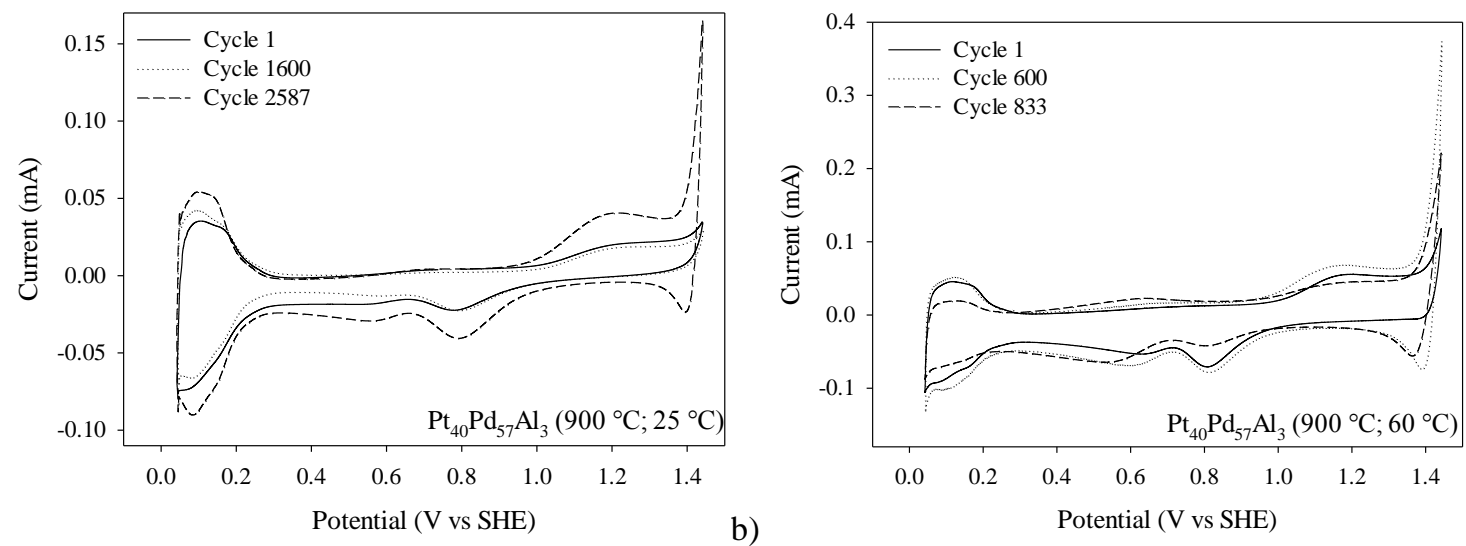

Figure 10: Consecutive cycling of (B)- $\mathrm{Pt}_{40} \mathrm{Pd}_{57} \mathrm{Al}_{3}$ annealed at $900{ }^{\circ} \mathrm{C}$ in $\mathrm{H}_{2} \mathrm{SO}_{4}$ at (a) $25^{\circ}$, and (b) $60{ }^{\circ} \mathrm{C}$.

\subsection{Further characterisation and discussion}

AFM and XPS analysis were conducted on the most promising binary ${ }^{21}$ and ternary thin film electrocatalysts in competing with pure $\mathrm{Pt}$ for $\mathrm{SO}_{2}$ electro-oxidation, with the aim being to gain more insight into the physical and electronic properties of these thin films. Pt thin films (as-deposited and the best performing annealed form) were also included in these analyses, serving as the primary reference/target electrocatalyst.

\subsubsection{AFM analysis}

AFM allows, among other things, meticulous observation and evaluation of the morphological and topographical characteristics of thin film surfaces. Three-dimensional (3D) AFM scans were recorded over a substrate area of 2 $\mu \mathrm{m} \times 2 \mu \mathrm{m}$, for each sample, at three different locations on the thin film. Roughness parameters were calculated from 2 different positions within each of the three individual locations so as to provide reliable average roughness values representative of the whole thin film surface. From the 2D and 3D AFM images shown in Table 1, it is clear that the thin films in the as-deposited form all exhibit a fine distribution of metal particles, adapting the profile of the underlying glassy carbon surface, with unavoidable grooves clearly visible resulting from polishing. Upon annealing the as-deposited thin films evolved from exhibiting a finely distributed appearance to clearly exhibiting different degrees of crystal formation with the least amount of change being visible for (I)- $700{ }^{\circ} \mathrm{C}$. (J)$800{ }^{\circ} \mathrm{C}$ transformed into a surface with clearly defined grain boundaries, evident of a polycrystalline nature ${ }^{21}$. (B) $-900{ }^{\circ} \mathrm{C}$ exhibited crystal growth of a totally different nature when compared to $(\mathrm{J})-800{ }^{\circ} \mathrm{C}$, with a type of random agglomerated distribution of small 'sheets' of crystals varying in orientation with sharp corners emerging from the surface. It is remarkable how only $\sim 3 \% \mathrm{Al}$ metal content can induce such an extreme difference in surface/bulk structure upon annealing. This type of crystal growth might be one of the reasons for observing a prominent improvement in catalyst performance for (B)- $-900{ }^{\circ} \mathrm{C}$, especially the stability performance observed for this electrocatalyst in a sulphuric acid environment for both $25^{\circ} \mathrm{C}$ and $60{ }^{\circ} \mathrm{C}$ (Figure 9), when compared to (I)$700{ }^{\circ} \mathrm{C}$ and $(\mathrm{J})-800{ }^{\circ} \mathrm{C}$.

Table 1: 2D and 3D AFM images for electrocatalysts (I)-Pt, (J)-Pt $\mathbf{P d}_{2}$, and (B)-Pt ${ }_{40} \mathbf{P d}_{57} \mathrm{Al}_{3}$

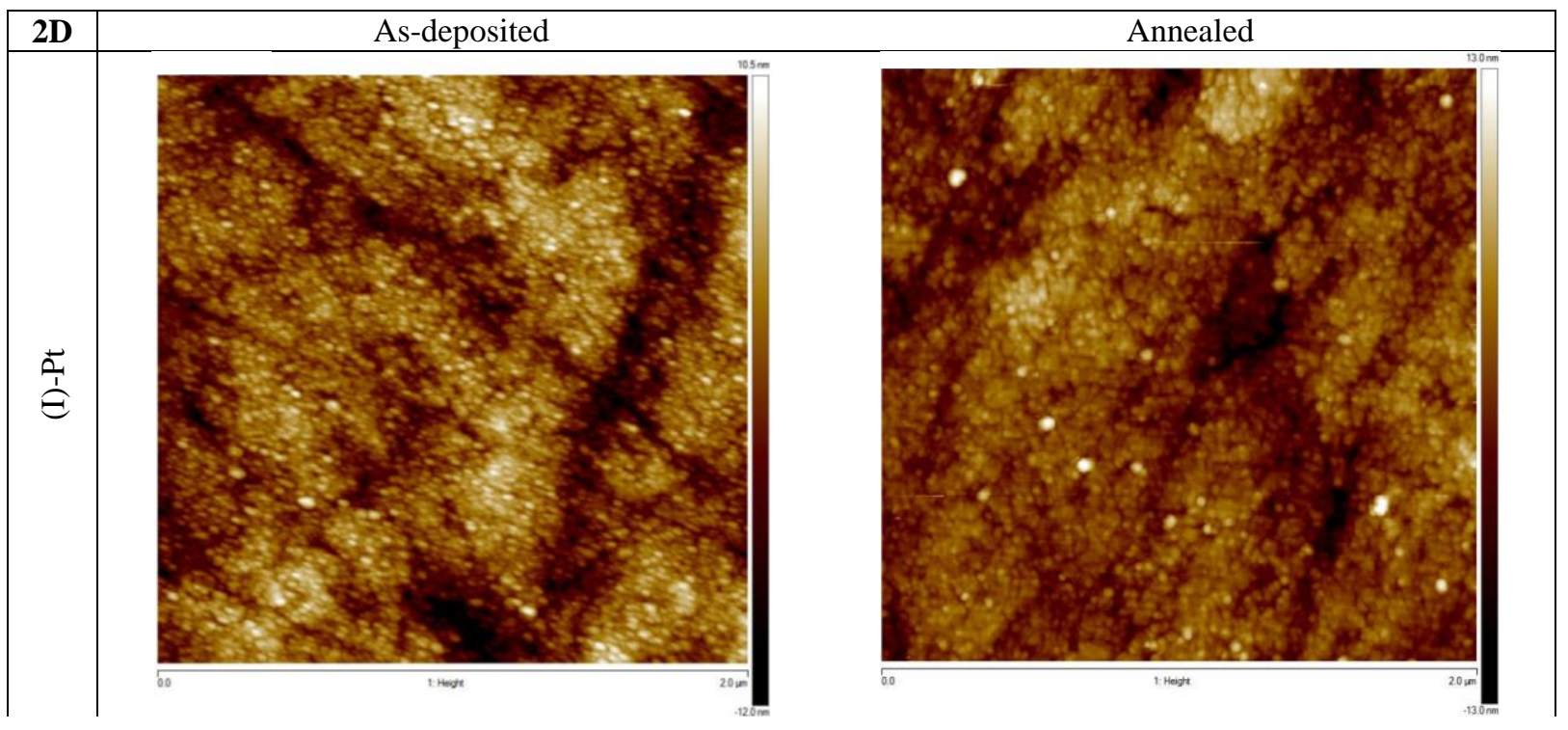



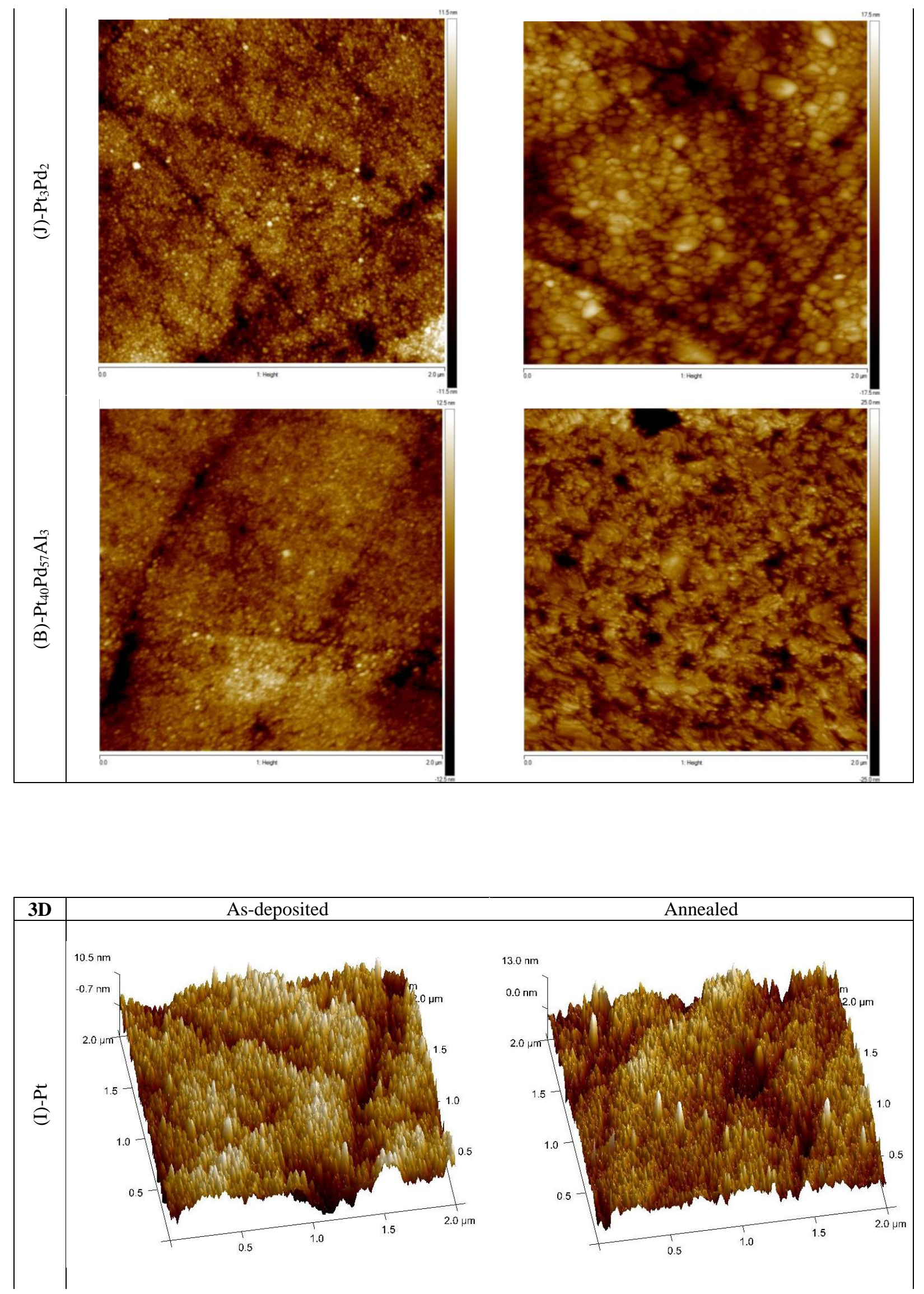


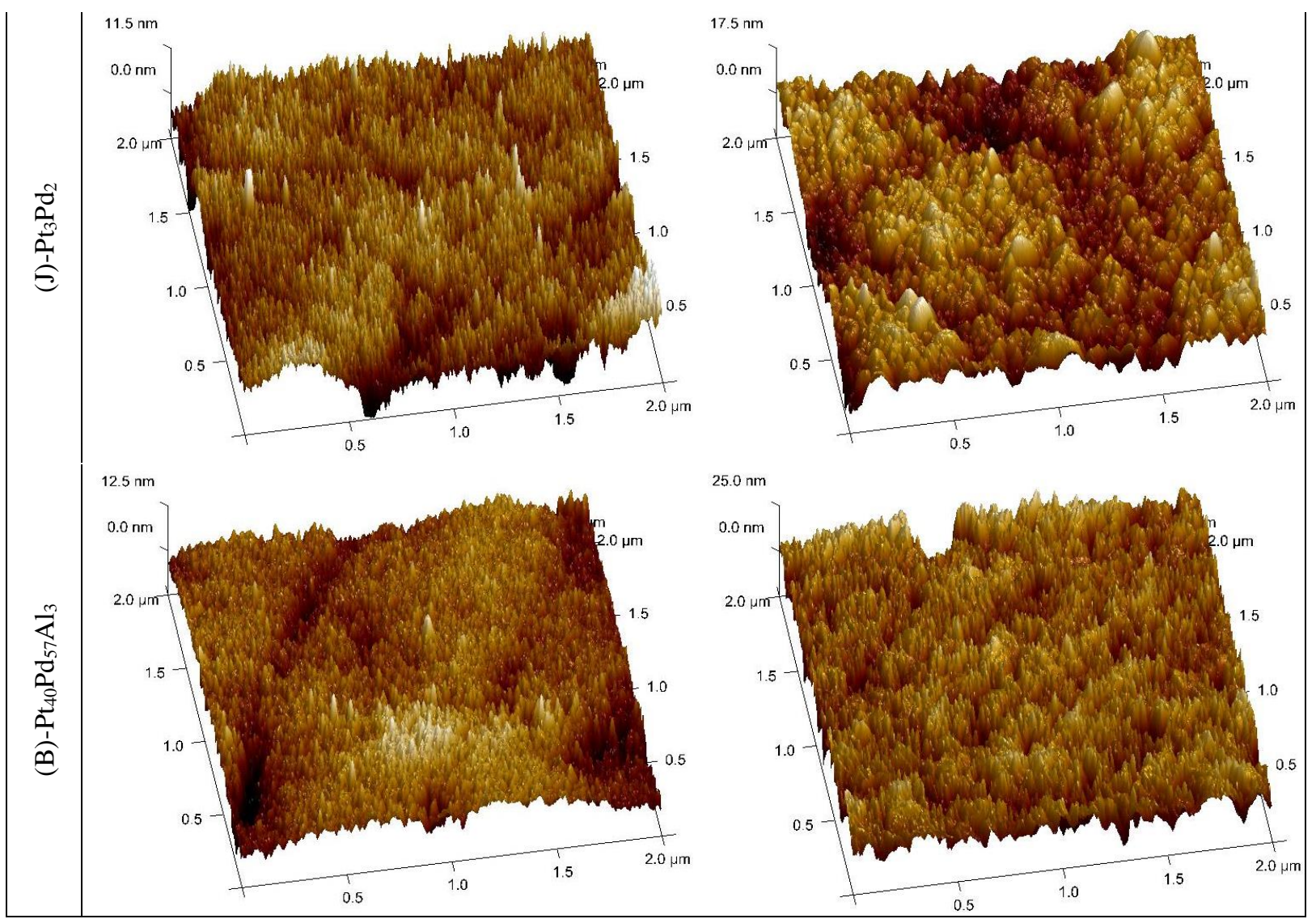

In addition to $2 \mathrm{D}$ and $3 \mathrm{D}$ imaging, the following surface roughness profile parameters (Figure 11) were acquired: (i) average roughness $\left(R_{a}\right)$, which is based on mean height roughness, (ii) vertical distance between the highest and lowest points $\left(\mathrm{R}_{\mathrm{t}}\right)$, and (iii) root mean square (RMS) of the distribution of surface height making it a bit more sensitive than $\mathrm{R}_{\mathrm{a}}{ }^{29}$.

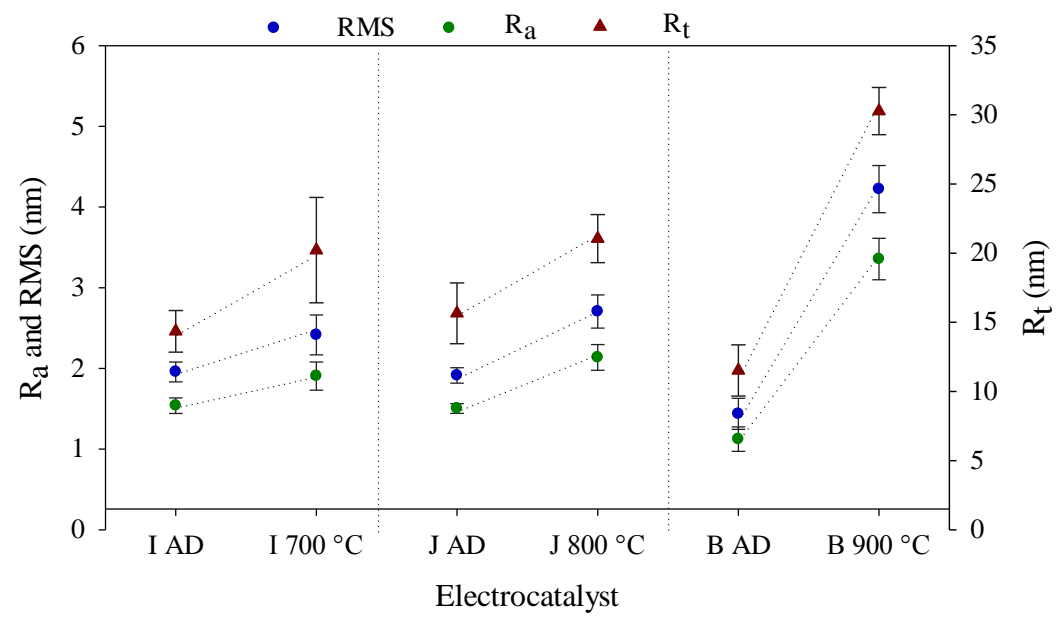

Figure 11: Surface roughness profile parameters of (I)- Pt as-deposited (I AD) and annealed at $700{ }^{\circ} \mathrm{C}$, (J)- $\mathrm{Pt}_{3} \mathrm{Pd}_{2}$ asdeposited (J AD) and annealed at $800{ }^{\circ} \mathrm{C}$, and $(\mathrm{B})$ - $\mathrm{Pt}_{40} \mathrm{Pd}_{57} \mathrm{Al}_{3}$ as-deposited (B AD) and annealed at $900{ }^{\circ} \mathrm{C}$.

In general, as is evident from Figure 11 , (I)-700 ${ }^{\circ} \mathrm{C}$ and $(\mathrm{J})-800{ }^{\circ} \mathrm{C}$ exhibited similar values for all the roughness parameters with (B)-AD showing a smoother surface (lower values) overall. As for the different annealed forms of the individual thin films, the roughness parameters all increased from the as-deposited state to the specific annealed form, with (B)-900 ${ }^{\circ} \mathrm{C}$ being the most influenced by annealing treatment and also exhibiting totally different crystal growth compared to (I)-700 ${ }^{\circ} \mathrm{C}$ and (J)-800 ${ }^{\circ} \mathrm{C}$ (Table $12 \mathrm{D}$ ). Overall, (B)-900 ${ }^{\circ} \mathrm{C}$ exhibited the highest roughness values for all three roughness parameters acquired, which has a direct and positive effect on 
the higher current output observed when compared to (I)-700 ${ }^{\circ} \mathrm{C}$ and (J)-800 ${ }^{\circ} \mathrm{C}$. The rapid thermal annealing of catalyst (B)- $900{ }^{\circ} \mathrm{C}$ has a positive influence on the performance and stability of this catalyst towards $\mathrm{SO}_{2}$ electrooxidation in a sulphuric acid environment.

\subsubsection{XPS}

In an attempt to further elucidate the observed electrocatalytic performance of the most promising binary ${ }^{21}$ and ternary thin film electrocatalysts, in competing with pure $\mathrm{Pt}$ for $\mathrm{SO}_{2}$ electro-oxidation, XPS surface analysis and depth profiling on the thin film samples were conducted so as to gain information regarding their composition and chemical environment. Knowing the overlapping that occurs between Pd3p3-O1s and Al2p-Pt4f peaks, high resolution spectra were collected to ensure that the best fitted quantified results are obtained, especially for materials J and B (cf. Electronic Supplementary Information (EIS) Figure S1 and S2 for fitted XPS spectra after $10 \mathrm{~s} \mathrm{Ar}^{+}$etching for $(\mathrm{B})-\mathrm{AD}$ and $(\mathrm{B})-900^{\circ} \mathrm{C}$ ). The fits were conducted subsequent to linear background subtraction using a product of Gaussian and Lorentzian functions, as defined in the AVANTAGE software. Figure 12 reveals comparative information for the $\mathrm{AD}$ and annealed states with regard to the extreme surface (top outer layer) of the thin films for Pt4f, Pd3d and Al2s. Figure 13 exhibits compositional information (derived from the C1s, O1s, $\mathrm{Pt}_{4} \mathrm{f}_{7 / 2}, \mathrm{Pd} 3 \mathrm{~d}_{3 / 2}$ and $\mathrm{Al} 2 \mathrm{~s}$ peak areas), related to the depth of the metallic Pt and Pt-based thin films deposited on glassy carbon as substrate. It must be kept in mind that (i) XPS remains a semi-quantitative analysis to follow atomic compositional change with depth (not to be directly correlated with previous EDX results), and (ii) XPS has an accuracy within 5 to $10 \%$ of absolute atomic $\%$ compositional information ${ }^{30}$.

In the as-deposited state, no shift in the $\mathrm{Pt}_{4 \mathrm{f}_{7 / 2}}$ peak at $\sim 71.15 \mathrm{eV}$ was observed for (I), (J) and (B), which is a direct indication that no significant change in the chemical environment occurred during/as a result of physical vapour deposition. Upon annealing, again no shift in the $\mathrm{Pt}_{4 \mathrm{f}_{7 / 2}}$ binding energy was observed for (I)-700 ${ }^{\circ} \mathrm{C}$ and (J)-800 ${ }^{\circ} \mathrm{C}$, however a clear change was observed for (B)-900 ${ }^{\circ} \mathrm{C}$, exhibiting a slight negative shift in the $\mathrm{Pt} 4 \mathrm{f}_{7 / 2}$ (Figure 11d) and $\mathrm{Pd} 3 \mathrm{~d}_{5 / 2}$ peaks ( Figure 11e), which could possibly be ascribed to the occurrence of metal-metal interactions as a result of annealing temperature ${ }^{31}$. In addition, (B)-900 ${ }^{\circ} \mathrm{C}$ (Figure $12 \mathrm{f}$ ) exhibited an increase in $\mathrm{Al}$ content at the surface (15 at. \%) when compared to (B)-AD (only 2 at. \%), which is expected if explained in terms of fundamental properties of monometallic metals (atomic radius) ${ }^{32}$. For the metals present in (B)-900 ${ }^{\circ} \mathrm{C}$, the order of decreasing size with regard to atomic radii is $\mathrm{Al}(143 \mathrm{pm})>\mathrm{Pt}(139 \mathrm{pm})>\mathrm{Pd}(137 \mathrm{pm})^{33}$. In general, lattice strain is expected to contribute to the segregation/migration of the atom with the largest atomic radius to the surface, which in the case of (B)- $900{ }^{\circ} \mathrm{C}$ is Al. This supports the observation obtained from XPS data that Al2s mainly appears on the extreme surface subsequent to annealing (Figure 11f), which clearly points towards the migration of $\mathrm{Al}$ to the surface upon annealing. 

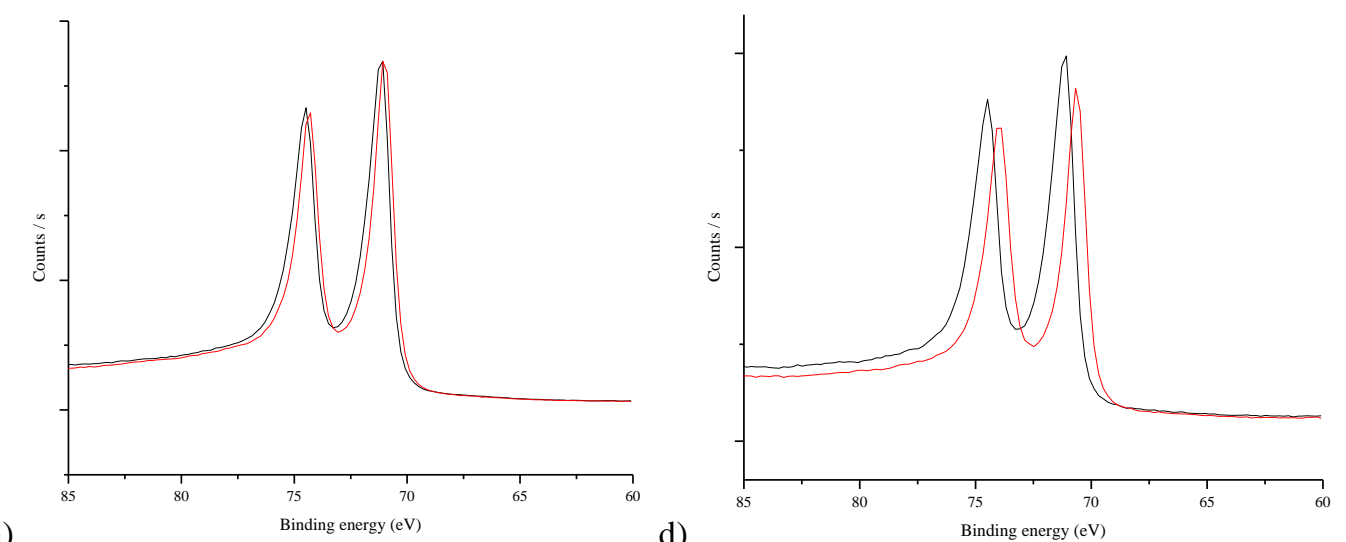

a)

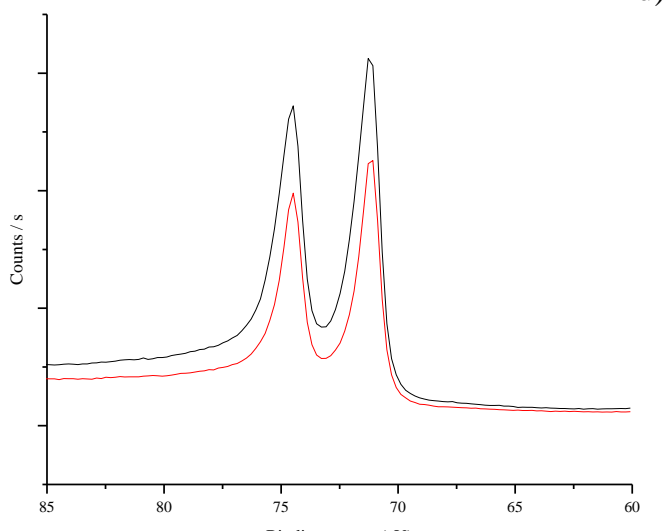

b)

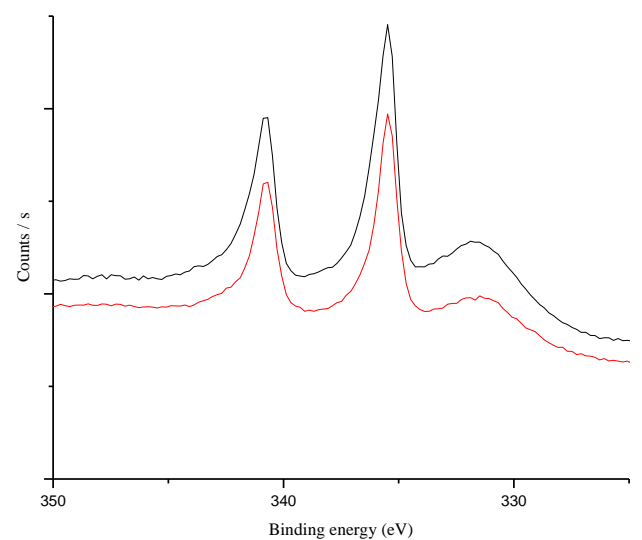

d)

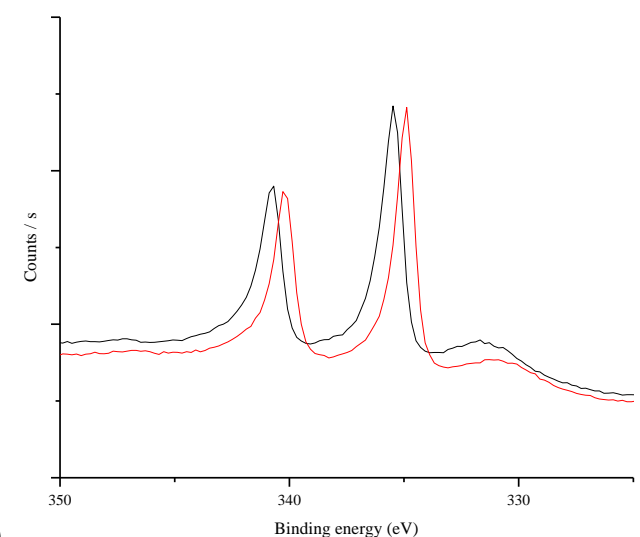

e)

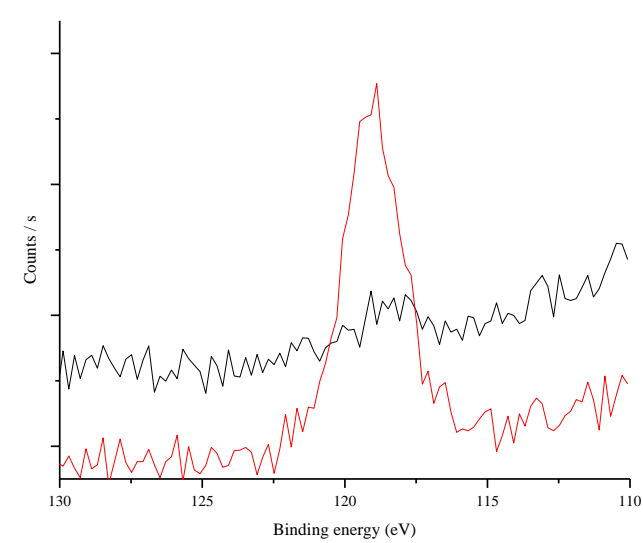

Figure 12: Pt4f, Pd3d and Al2s XPS spectra on the extreme surface, i.e. the top outer layer, of both the as-deposited (AD) (black curve) and annealed states (red curve) of (I)-Pt (a), (J)-Pt3 Pd2, (b, c) and (B)-Pt $\mathbf{P d}_{40} \mathrm{Pd}_{57} \mathrm{Al}_{3}\left(\mathrm{~d}_{1}, \mathrm{e}, \mathrm{f}\right)$.

While the previous XPS measurements (Figure 12) focused on the surface, depth profiles of the Pt and Pt-based samples (Figure 13) were obtained by combining a sequence of $\mathrm{Ar}^{+}$ion gun etch cycles with XPS measurements from the current exposed surface. The objective of obtaining depth profiles was to validate that the observed electrocatalytic performance was not as a result of a 'skin' formed, as a result of severe segregation/migration to the surface, but rather being the result of a homogeneous composition throughout the depth of the thin film. The first observation for all the electrocatalysts, in both the as-deposited and annealed states, is (i) the presence of unescapable C, N, Si and Cl impurities, due to ambient pollution on the metal surface layer, disappearing after only $10 \mathrm{~s}$ of $\mathrm{Ar}^{+}$etching, and (ii) a constant $\sim 55 \mathrm{~nm}$ thin metallic layer (validating the calibrated sputtered layer of $\sim 60 \mathrm{~nm}$ ) recorded by XPS etching for all the analysed thin films. Subsequent to $\mathrm{Ar}^{+}$etching through the thin metallic film, it is clear that at a depth of $\sim 40 \mathrm{~nm}$ carbon from the substrate appears. Carbon, however, is present almost throughout the depth of the annealed surfaces (especially sample (B)- $900^{\circ} \mathrm{C}$ ), which can be explained either by possible diffusion of the substrate through the $\mathrm{Pt} / \mathrm{Pd} / \mathrm{Al}$ thin film at high temperature (which is unlikely as these specific glassy carbon inserts are stable under high temperatures) or as a result of XPS detecting possible 'exposed' substrate carbon as a result of the roughness of the (B)- $900^{\circ} \mathrm{C}$ thin film $\left(\mathrm{R}_{\mathrm{t}}\right.$ around $30 \mathrm{~nm}$, Figure 11). It is furthermore evident that contraction of the different sputtered layers occur upon annealing with increased contraction as the temperature increases. 

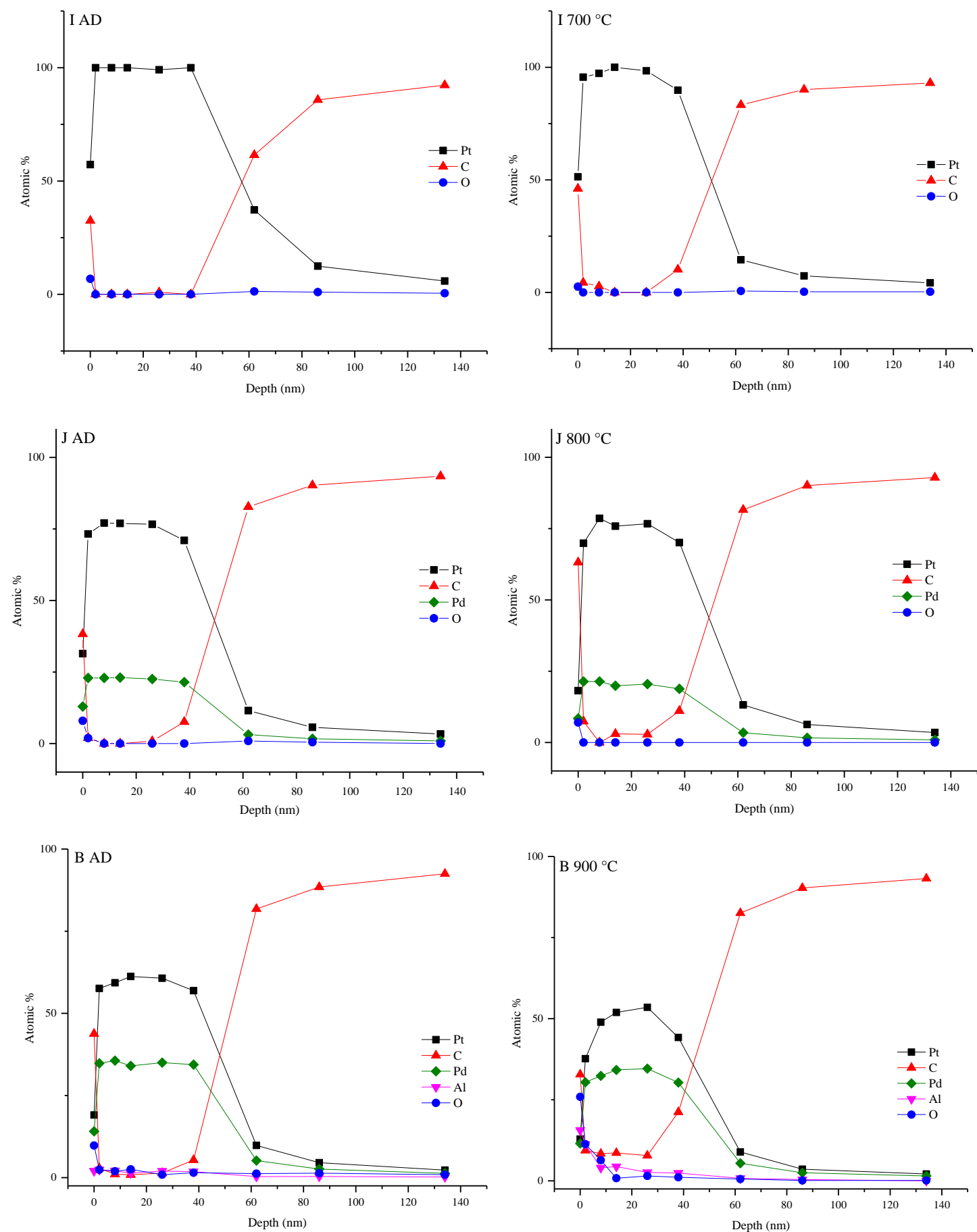

Figure 13: Depth profiles of (I)-Pt, (J)-Pt $3 \mathrm{Pd}_{2}$ and (B)-Pt ${ }_{40} \mathrm{Pd}_{57} \mathrm{Al}_{3}$, for both the as-deposited (AD) and annealed states. The etch-rate was estimated $0.2 \mathrm{~nm} / \mathrm{s}$ on each material.

For (B), Al seems to be in the oxidised state throughout the entire thickness of the layer (118.5 eV binding energy Figure 12f, only data for the top layer is shown). As Al gets oxidised easily in air, it is very probable that the samples were oxidised from the moment when the thin films were exposed to air. In addition, XPS depth profiling for (B) $-900^{\circ} \mathrm{C}$ supports the previous observation (Figure 12f) of a degree of migration of Al towards the surface after annealing and that all three metals are present throughout the depth of the thin film. Concerning Pd3 $\mathrm{d}_{5 / 2} \mathrm{Peak}$ fitting (cf. EIS Figure S1 and S2), the absence of PdO bonding usually located at $337 \mathrm{eV}$ is confirmed ${ }^{34}$ as the maximum component is $\mathrm{Pd}$ metal at around $335 \mathrm{eV}$, while another $1 \mathrm{eV}$ higher $(\sim 336 \mathrm{eV})$ could be attributed to $\mathrm{Pd}-\mathrm{O}-\mathrm{X}$ bonding namely $\mathrm{Pd}-\mathrm{O}-\mathrm{Al}$.

As thin film (B), i.e. $\mathrm{Pt}_{40} \mathrm{Pd}_{57} \mathrm{Al}_{3}$, presented itself as being a competitive electrocatalyst for $\mathrm{SO}_{2}$ electro-oxidation, measured against $\mathrm{Pt}$ and the previously identified $\mathrm{Pt}_{3} \mathrm{Pd}_{2}$ composition, XRD spectra were furthermore recorded 
for (B)-AD and (B)- $900{ }^{\circ} \mathrm{C}$ (cf. EIS Figure S3). (B)-AD is concluded to consist of a PtPd cubic phase, whereas (B) $-900^{\circ} \mathrm{C}$ consist of a possible $\mathrm{Pt}_{2.84} \mathrm{Al}_{1.16}$ cubic phase that may support the slight negative shift observed for the $\mathrm{Pt}_{4} \mathrm{f}_{7 / 2}$ (Figure 11d) and $\mathrm{Pd} 3 \mathrm{~d}_{5 / 2}$ peaks (Figure 11e), which are indicative of alloy formation.

\section{Conclusion}

As is evident from literature, only a limited number of surfaces have been investigated thus far for catalysing the electro-oxidation of aqueous $\mathrm{SO}_{2}$. It is furthermore clear that widespread disagreement and non-reproducible behavior exist ${ }^{24}$, as this reaction is very sensitive and highly influenced by the prevailing conditions (electrode material, $\mathrm{pH}$, temperature, preconditioning, pressure, applied anodic potential, etc.). From our investigation, identifying a possible alternative anode catalyst that can compete with pure $\mathrm{Pt}$, it is clear that a lot of scope and room for improvement still exist for improving the catalytic activity and stability of the electrocatalyst. In general, it is primarily the surface properties of a catalyst in conjunction with the secondary bulk effects, which are credited for any observed catalytic improvements/weakening. We have highlighted the influence that a secondary/tertiary metal, in conjunction with annealing, can have on the catalytic performance of the thin film by effecting only slight changes in composition and temperature treatment.

The addition of a third component to the noble metals $\mathrm{Pt}$ and $\mathrm{Pd}$, in the form of $\mathrm{Al}$, i.e. $\mathrm{Pt}_{\mathrm{x}} \mathrm{Pd}_{\mathrm{y}} \mathrm{Al}_{\mathrm{z}}$, enhanced the electrocatalytic performance towards the electro-oxidation of aqueous $\mathrm{SO}_{2}$ with the Al content kept below $\sim 3 \%$. In excess of $\sim 3 \% \mathrm{Al}$ the electrocatalytic performance was severely hampered. Overall onset potential, however, did not improve significantly for any of the evaluated electrocatalysts, while improvements in current output and stability (lasting 1.4 times longer than both pure $\mathrm{Pt}$ (the (I)-700 ${ }^{\circ} \mathrm{C}$ sample) and $\mathrm{Pt}_{3} \mathrm{Pd}_{2}$ (the $(\mathrm{J})-800{ }^{\circ} \mathrm{C}$ sample) was achieved specifically for $\mathrm{Pt}_{40} \mathrm{Pd}_{57} \mathrm{Al}_{3}$ (the (B)- $900{ }^{\circ} \mathrm{C}$ sample), both in $25{ }^{\circ} \mathrm{C}$ and $60{ }^{\circ} \mathrm{C}$ testing environments. We have shown that electrocatalytic activity for the electro-oxidation of aqueous $\mathrm{SO}_{2}$ can be achieved by substantially lowering the Pt content in that current density (mA.mg $\mathrm{Pt}^{-1}$ ) increased from 108.11 to 181.21 and finally to 396.73 for $\mathrm{Pt}, \mathrm{Pt}_{3} \mathrm{Pd}_{2}$ and $\mathrm{Pt}_{40} \mathrm{Pd}_{57} \mathrm{Al}_{3}$ respectively, indicating an increase in activity that correlates with a decrease in Pt content.

Furthermore, additional information obtained from XPS analysis has shown that $\mathrm{Pt}_{40} \mathrm{Pd}_{57} \mathrm{Al}_{3}\left((\mathrm{~B})-900{ }^{\circ} \mathrm{C}\right)$ exhibited an increase in $\mathrm{Al}$ content at the surface ( 15 at. \%) when compared to (B)-AD (only $\sim 2$ at. \%) although no sign of a distinctive skin of one metal (or more in the case of $\mathrm{Pt}_{40} \mathrm{Pd}_{57} \mathrm{Al}_{3}$ ) was present near the surface for the $\mathrm{Pt}_{3} \mathrm{Pd}_{2}$ and $\mathrm{Pt}_{40} \mathrm{Pd}_{57} \mathrm{Al}_{3}$ thin films (as-deposited and annealed). This confirmed that the observed activity of the thin films was a result of all the metals being present in the thin film surface. XRD analysis of the annealed $\mathrm{Pt}_{40} \mathrm{Pd}_{57} \mathrm{Al}_{3}$ thin film ((B)-900 ${ }^{\circ} \mathrm{C}$ ) has highlighted the presence of some degree of alloy formation.

The power of alternately employing combinatorial and high-throughput methods with conventional electrochemical and characterisation methods, for electrocatalysts development, has clearly been shown, and resulted in the identification of a catalyst that contains a lot less platinum while exhibiting increased catalytic activity and stability. Combining, among other things, the sensitivity of this reaction to the surface where oxidation occurs, with the mechanistic complexity of this reaction ${ }^{35}$ ( proposed mechanisms include, indirect oxidation via (i) a dithionate intermediate ${ }^{36-38}$ or (ii) involving bulk $\mathrm{SO}_{2}$ and an unspecified $\mathrm{S}$ (VI) intermediate ${ }^{39}$, and direct oxidation via adsorbed reactant ${ }^{37}$ ), a specific active catalysts of interest will be better understood by in depth mechanistic investigation taking into account various factors such as temperature, acid concentration, sulphur coverage etc. It is however relevant to mention, that the majority of mechanistic studies on $\mathrm{SO}_{2}$ oxidation were conducted on platinum and single component electrode materials. Based on the amount of effort devoted to the mechanistic understanding of Pt catalysing $\mathrm{SO}_{2}$ oxidation, do these studies reveal the complexity of this reaction, proving that the necessary mechanistic characterisation of this identified multi-component $\mathrm{Pt}_{40} \mathrm{Pd}_{57} \mathrm{Al}_{3}$ electrocatalyst evident to be challenging and will require meticulous and repeatable evidence to be fundamentally sound.

\section{Acknowledgements}

The financial assistance of the National Research Foundation (NRF) towards this research is hereby acknowledged (UNIQUE GRANT NO: 92704). Opinions expressed and conclusions arrived at, are those of the authors and are not necessarily to be attributed to the NRF. The assistance of Dr. L. Tiedt with EDX, Mr. H.S. Kotzé with annealing and Me. L. Swartzberg with conventional electrochemistry runs, is gratefully acknowledged. In addition we want to express our gratitude to Mr. E. Lebraud (engineer, ICMCB UPR 9048, 87 av. Albert Schweitzer, 33608 Pessac Cédex France) for assistance with XRD.

\section{References}


1. $\quad$ C.-J. Winter, Int. J. Hydrogen Energy, 2009, 34, S1-S52.

2. K. L. Kovacs, G. Maroti and G. Rakhely, Int. J. Hydrogen Energy, 2006, 31, 1460-1468.

3. M. A. Rosen and D. S. Scott, Int. J. Hydrogen Energy, 1998, 23, 653-659.

4. P. Sivasubramanian, P. R. Ramaraja, F. J. Freire, C. E. Holland and J. W. Wiedner, Int J Hydrogen Energy, 2007, 32, 436-468.

5. R. Chaubey, S. Sahu, O. O. James and S. Maity, Renew. Sust. Energy Rev., 2013, 23, 443-462.

6. L. Xue, P. Zhang, S. SChen and L. Wang, Chem. Eng. Process., 2015, 89, 70-74.

7. $\quad$ M. B. Gorensek and W. A. Summer, Int. J. Hydrogen Energ., 2009, 34, 4097-4114.

8. J. W. Weidner, J. Appl. Electrochem., 2016, DOI: 10.1007/s10800-016-0962-0, 1-11.

9. G. H. Farbman, The conceptual design of an integrated nuclear-hydrogen production plant using the sulfur cycle water decomposition system, Report NASA-CR-134976, NASA contractor report, NASA-CR-134976, 1976.

10. M. B. Gorensek and W. A. Summer, in Nuclear hydrogen production handbook, eds. L. Y. Xing and H. Ryutaro, CRC Press, United States of America, 2011, ch. 499-538.

11. P. W. T. Lu, R. L. Ammon and G. H. Parker, A study on the electrolysis of sulfur dioxide and water for the sulfur cycle hydrogen production process, NASA contractor report, NASA-CR163517, 1980.

12. L. C. Brown, J. E. Funk and S. K. Showalter, Initial screening of thermochemical watersplitting cycles for high efficiency generation of hydrogen fuels using nuclear power, General Atomics, Report No. GA-A23373, April 2000.

13. R. C. Weast, CRC Handbook of Chemistry and Physics, 70th ed., CRC Press Inc, Boca Raton, Florida, 1989-1990.

14. B. D. Struck, R. Junginger, D. Boltersdorf and J. Gehrmann, Int J Hydrogen Energ, 1980, 5, 487-497.

15. J. A. Staser, M. B. Gorensek and J. W. Weidner, J. Electrochem. Soc., 2010, 157, B952-B958.

16. J. A. Allen, G. Rowe, J. T. Hinkley and S. W. Donne, Int. J. Hydrogen Energ., 2014, 39, 1137611389.

17. M. B. Gorensek, W. A. Summer, C. O. Bolthrunis, E. J. Lahoda, D. T. Allen and R. Greyvenstein, Hybrid Sulfur Process Reference Design and Cost Analysis - Final Report SRNLL1200-2008-00002. Rev 1, 2009.

18. L. Xue, P. Zhang, S. Chen and L. Wang, Int J Hydrogen Energ, 2014, 39, 14196-14203.

19. S. Lee, C. Kim, W. Cho, K. Kang, C. Park and K. Bae, Int. J. Hydrogen Energ., 2009, 34, 47014707.

20. A. Falch, V. Lates and R. J. Kriek, Electrocatalysis, 2015, 6, 322-380.

21. A. Falch, V. A. Lates, H. S. Kotze and R. J. Kriek, Electrocatalysis, 2016, 7, 33-41.

22. A. R. Despic, D. M. Drazic, M. M. Purenovic and N. Cikovic, J. Appl. Electrochem., 1976, 6, 527-542.

23. J. Lee, J. Appl. Electrochem., 1995, 25, 353-357.

24. J. A. O`Brien, J. T. Hinkely, S. W. Donne and S. Lindquist, Electrochem Acta, 2010, 55, 573591.

25. J. A. O'Brien, J. T. Hinkley and S. W. Donne, Electrochim. Acta., 2011, 56, 4224-4230.

26. J. S. Cooper and P. J. McGinn, J. Power Sources, 2006, 163, 330-338.

27. R. Potyrailo, K. Rajan, K. Stoewe, I. Takeuchi, B. Chisholm and H. Lam, ACS Comb. Sci., 2011, 13, 579-633.

28. J. S. Cooper and P. J. McGinn, App. Surf. Sci., 2007, 254, 662-668.

29. B. R. Kumar and T. S. Rao, Dig. J. Nanomater. Bios., 2012, 7, 1881-1889.

30. P. Silva-Bermudez, G. Ramirez and S. E. Rodh, Bio-tribocorrosion in biomaterials and medical implants, Woodhead publishing limited, Cambridge, UK, 2013.

31. T. Lopes, E. Antolini and E. R. Gonzalez, Int. J. Hydrogen Energ., 2008, 33, 5563-5570.

32. J. R. Croy, S. Mostafa, L. Hickman, H. Heinrich and B. R. Cuenya, Appl. Catal. A: Gen, 2008, 350, 207-216.

33. M. Weller, T. Overton, J. Rourke and F. Amstrong, Inorganic chemistry $6^{\text {th }}$ edition, Oxford Univeristy Press, United Kingdom, 2014.

34. E. Garrido, C. Aymonier, L. Roiban, O. Ersen, C. Labrugère, P. Gaillard and M. LamirandMajimel, J. Supercrit. Fluids, 2015, 101, 110-116. 
35. J. O’Brien, J. Hinkley and S. Donne, J. Electrochem. Soc., 2010, 157, F111-F115.

36. C. Audry and M. Vionov, Electrochim. Acta, 1980, 25, 299-301.

37. C. Quijada, A. Rodes, J. Vazquez, J. Perez and A. Aldaz, J. Electroanal. Chem., 1995, 398, 105-115.

38. A. J. Appleby and B. Pinchon, J. Electroanal. Chem., 1979, 95, 59-71.

39. E. T. Seo and D. T. Sawyer, Electrochem Acta, 1965, 10, 239-252. 